\title{
Liquid-liquid extraction of succinate using a dicopper cryptate
}

Riccardo Mobili, Sonia La Cognata, Francesca Merlo, Andrea Speltini, Massimo Boiocchi, Teresa Recca, Louis James Maher III, Valeria Amendola

Submitted date: 01/02/2020 Posted date: 04/02/2020

Licence: CC BY-NC-ND 4.0

Citation information: Mobili, Riccardo; La Cognata, Sonia; Merlo, Francesca; Speltini, Andrea; Boiocchi, Massimo; Recca, Teresa; et al. (2020): Liquid-liquid extraction of succinate using a dicopper cryptate. ChemRxiv. Preprint. https://doi.org/10.26434/chemrxiv.11786784.v1

The extraction of the succinate dianion from a neutral aqueous solution into dichloromethane is obtained using a lipophilic cage-like dicopper(II) complex as the extractant. The quantitative extraction exploits the high affinity of the succinate anion for the cavity of the azacryptate. The anion is effectively transferred from the aqueous phase, buffered at $\mathrm{pH} 7$ with HEPES, into dichloromethane. A 1:1 extractant:anion adduct is obtained. Extraction can be easily monitored by following changes in the UV-visible spectrum of the dicopper complex in dichloromethane, and by measuring the residual concentration of succinate in the aqueous phase by HPLC-UV. Considering i) the relevance of polycarboxylates in biochemistry, as e.g. normal intermediates of the TCA cycle, ii) the relevance of dicarboxylates in the environmental field, as e.g. waste products of industrial processes, and iii) the recently discovered role of succinate and other dicarboxylates in pathophysiological processes including cancer, our results open new perspectives for research in all contexts where selective recognition, trapping and extraction of polycarboxylates is required.

File list (2) 


\title{
Succinate extraction from water using a cage-like dicopper complex
}

\author{
Riccardo Mobili, ${ }^{1 \ddagger}$ Sonia La Cognata, ${ }^{1 \ddagger}$ Francesca Merlo ${ }^{1}$, Andrea Speltini ${ }^{2}$, Massimo Boiocchi, ${ }^{3}$ Teresa \\ Recca, ${ }^{3}$ Louis J. Maher III $^{4}$ and Valeria Amendola ${ }^{1 *}$ \\ ${ }^{1}$ Department of Chemistry, v.le T. Taramelli 12, Pavia, Italy; ${ }^{2}$ Department of Drug Sciences, via Taramelli 12, Pavia, Italy; \\ ${ }^{3}$ Centro Grandi Strumenti, via A. Bassi 21, Pavia, Italy; ${ }^{4}$ Department of Biochemistry and Molecular Biology, Mayo Clinic, \\ Rochester, MN, USA
}

\begin{abstract}
The extraction of the succinate dianion from a neutral aqueous solution into dichloromethane is obtained using a lipophilic cage-like dicopper(II) complex as the extractant. The quantitative extraction exploits the high affinity of the succinate anion for the cavity of the azacryptate. The anion is effectively transferred from the aqueous phase, buffered at $\mathrm{pH} 7$ with HEPES, into dichloromethane. A 1:1 extractant:anion adduct is obtained. Extraction can be easily monitored by following changes in the UV-visible spectrum of the dicopper complex in dichloromethane, and by measuring the residual concentration of succinate in the aqueous phase by HPLC-UV. Considering i) the relevance of polycarboxylates in biochemistry, as e.g. normal intermediates of the TCA cycle, ii) the relevance of dicarboxylates in the environmental field, as e.g. waste products of industrial processes, and iii) the recently discovered role of succinate and other dicarboxylates in pathophysiological processes including cancer, our results open new perspectives for research in all contexts where selective recognition, trapping and extraction of polycarboxylates is required.
\end{abstract}

Polycarboxylates are relevant in the biological, industrial and environmental fields. ${ }^{1}$ In particular, these anionic species are natural cellular metabolites with roles as intermediates of the tricarboxylic acid (TCA) cycle. ${ }^{2,3}$ For these reasons, molecular systems capable of selectively recognizing target polycarboxylates have attracted attention in the supramolecular chemistry field over many years. ${ }^{4}$ ${ }^{15}$ Interest will undoubtedly grow because of the recent medical recognition of pathological the roles of some dicarboxylates beyond normal metabolism. ${ }^{2,3,16,17}$ For instance, succinate plays a crucial role in the TCA cycle, where it is oxidized for electron delivery to the respiratory chain, and in heme and itaconate metabolism, and the "GABA ( $\gamma$-aminobutyric acid) shunt." Succinate has recently been recognized as an oncometabolite whose accumulation drives pathophysiological processes including cancer. ${ }^{2,3,16,18}$

Molecular receptors are appreciated as powerful tools for the selective recognition and binding of anionic guests in competing media. ${ }^{7,10,19-25}$ Research in the field has led to the development of i) a plethora of anion sensors, anion-responsive materials, organocatalytic processes involving anion complexation, ii) systems for the selective liquid-liquid or solid-liquid extraction of the target anion, and iii) compounds to be applied as anion transporters across cell membranes. ${ }^{14,15,26,27}$ The latter applications have generally involved the extraction ${ }^{28-33}$ and/or transport of halides ${ }^{27,34-39}$ - chloride, in particular - or oxoanions ${ }^{40-42}$. Despite strong interest in the manipulation of polycarboxylates, application of molecular receptors in the selective extraction of these relevant species is rare. ${ }^{27,43,44}$ Extraction of polycarboxylates from a neutral aqueous solution into an apolar solvent is both interesting and challenging. In particular, the process must be both electroneutral and selective, i.e. charge neutrality must be maintained and the extractant should discriminate among similar guests, e.g. species differing only for one methylene group on the alkyl chain. ${ }^{14}$

In this work, we demonstrate that both challenges can be overcome by implementing a cage-like dicopper(II) complex with a lipophilic framework, whose cavity is shaped to selectively accommodate the target dicarboxylate species. For this study, we chose succinate as the target anion, because of its established role as an oncometabolite through inhibition of dioxygenases involved in epigenetics and the hypoxic response.

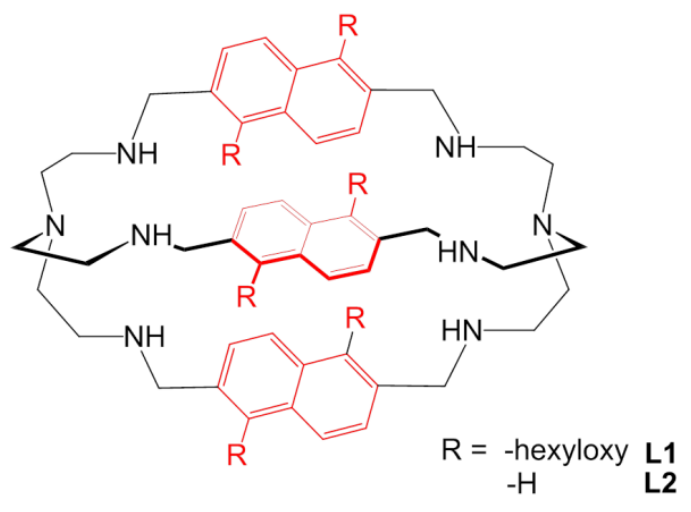

Figure 1. Azacryptands studied in this work. 
The lipophilic azacryptand L1 (Figure 1) was synthesized by [2+3] Schiff condensation of tren with the proper dialdehyde, followed by reduction of the imine bonds with $\mathrm{NaBH}_{4}$ (see S.I. for details). The final polyamine $\mathbf{L 1}$ was characterized by potentio-metric titrations in dioxane/water $20 \% \mathrm{v} / \mathrm{v},[\mathrm{TBA}] \mathrm{NO}_{3} 0.05 \mathrm{M}, 25{ }^{\circ} \mathrm{C}$. These studies, performed on both the ligand alone and in the presence of 2 eqv. $\mathrm{Cu}\left(\mathrm{NO}_{3}\right)_{2}$, allowed determination of the protonation and complexation constants reported in Table $\mathrm{S} 1$. The $\left[\mathrm{Cu}_{2} \mathbf{L 1}\right]^{4+}$ species was found to be the major complex (> 99\%) in solution between pH 6 and 10 (Figure 2). The UV-vis. spectrum of $\left[\mathrm{Cu}_{2} \mathbf{L 1}\right]^{4+}$ is characterized by a typical d-d band around $900 \mathrm{~nm}$ and a shoulder at $730 \mathrm{~nm}$, due to the coordination of the copper(II) ions to the tren subunits, with water molecules completing the penta-coordination sphere of the metal centers. The binding of $\mathrm{Cu}(\mathrm{II})$ ions to the tren compartments is also accompanied by the development of $\mathrm{N}_{\mathrm{sec}} \rightarrow \mathrm{Cu}$ (II) (LMCT) bands near $330 \mathrm{~nm}$. The profile of the molar absorbance at $885 \mathrm{~nm} v s$. pH (see red triangles in Figure 2) is superimposable on the curve for percent abundance of $\left[\mathrm{Cu}_{2} \mathbf{L} \mathbf{1}\right]^{4+}$ vs. $\mathrm{pH}$ in the distribution diagram.

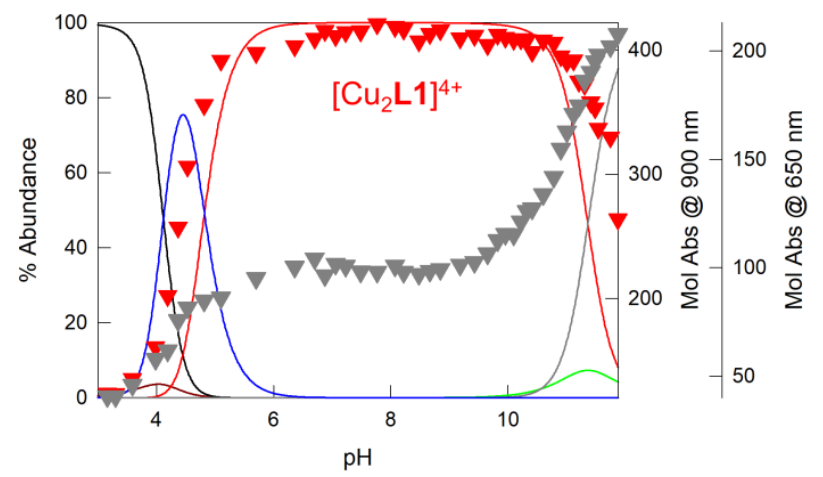

Figure 2. Distribution diagram showing species present at equilibrium during potentiometric titration of $\mathbf{L 1}(0.4 \mathrm{mM})$ in presence of 2 eqv. Cu(NO$)_{2}$ with the superimposed $\mathrm{pH}$-spectrophotometric profiles of $\mathrm{Mol} \mathrm{Abs}$ at 885 and $650 \mathrm{~nm}$ (red and green triangles, respectively) vs. $\mathrm{pH}$, in dioxane/water $20 \% \mathrm{v} / \mathrm{v}$, $\left.0.05 \mathbf{M}^{2} \mathrm{TBA}\right] \mathrm{NO}_{3}\left(\mathrm{~T} 2{ }^{\circ} \mathrm{C}\right)$. The lines in the diagram correspond to the species: $\mathrm{H}_{6} \mathbf{L 1}^{6+}$, black; $\mathrm{H}_{5} \mathbf{L} \mathbf{1}^{5+}$, dark red; $[\mathrm{Cu} 2 \mathbf{L 1}]^{4+}, \operatorname{red} ;\left[\mathrm{Cu} \mathbf{L u}_{2} \mathbf{L}(\mathrm{OH})\right]^{3+}$, green; $\left[\mathrm{Cu}_{2} \mathbf{L 1}(\mathrm{OH})_{2}\right]^{2+}$, grey.

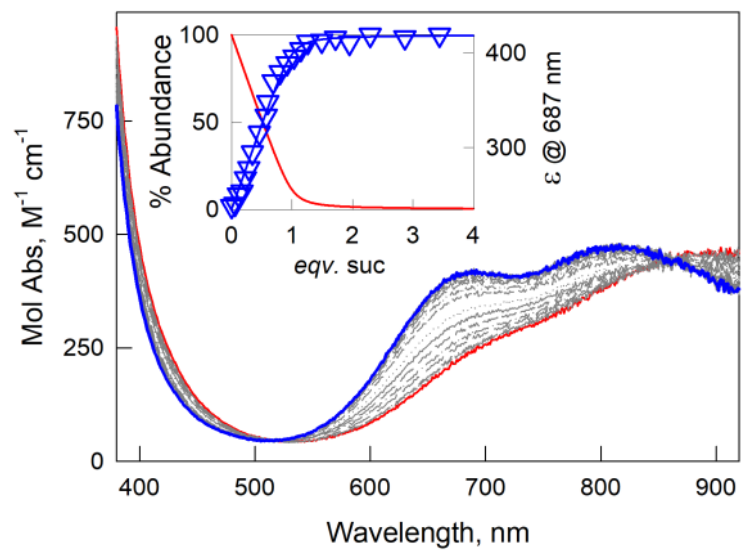

Figure 3. Family of spectra taken over the course of the UV-vis. titration of $\left[\mathrm{Cu}_{2} \mathbf{L 1}\right]^{4+}\left(50 \mu \mathrm{M}\right.$ ) with a solution of $\mathrm{H}_{2}$ suc in dioxane/water $20 \% \mathrm{v} / \mathrm{v}$, buffered at pH 7 by HEPES $0.025 \mathrm{M}\left(\mathrm{T} 25^{\circ} \mathrm{C}\right.$, path length: $\left.10 \mathrm{~cm}\right)$. Initial spectrum and final spectrum: red and blue lines, respectively. Inset figure: plot of $\varepsilon$ (i.e. $\mathrm{Mol}$ Abs) at $687 \mathrm{~nm}$ vs. eqv. of the added guest (triangles), superimposed to the distribution diagram of the species calculated for a log $K_{11}=5.60$; $\%$ $\left[\mathrm{Cu}_{2} \mathbf{L 1}\right]^{4+}$ (red line) and $\left[\mathrm{Cu}_{2} \mathbf{L} \mathbf{1}(\mathrm{suc})\right]^{2+}$ (blue line) vs. eqv. of succinate. See S.I. for details.

The anion binding trend of $\left[\mathrm{Cu}_{2} \mathbf{L 1}\right]^{4+}$ was then investigated with dicarboxylates of various structures and chain lengths. UV-vis. titrations were performed in dioxane/water solution $20 \% \mathrm{v} / \mathrm{v}$, buffered at $\mathrm{pH} 7$ by HEPES $0.025 \mathrm{M}\left(\mathrm{T}=25^{\circ} \mathrm{C}\right)$. Appreciating that organic solvents in the aqueous mixture may alter dissociation equilibria, we determined $\mathrm{p} K_{a}$ values for two relevant acids, $\mathrm{H}_{2}$ suc and $\mathrm{H}_{2}$ glut, through potentiometric titrations in dioxane/water $20 \% \mathrm{v} / \mathrm{v}, 0.05 \mathrm{M}$ [TBA] $\mathrm{NO}_{3}\left(\mathrm{~T}=25{ }^{\circ} \mathrm{C}\right.$; see S.I.). As expected, complete deprotonation of $\mathrm{H}_{2} \mathrm{Suc}$ and $\mathrm{H}_{2}$ glut was obtained only at $\mathrm{pH}>8$ (see S.I., Figures $\mathrm{S} 2$ and S3), while the abundance of the corresponding dicarboxylates in pure water was already greater than $99 \%$ at $\mathrm{pH} 7$.

Even if the deprotonation of dicarboxylic acids is disfavored in the chosen aqueous mixture, the coordination of the corresponding dianion to the metal centers within the cavity of the cage may provide sufficient driving force to promote complete deprotonation. This was confirmed by UV-vis. titrations for $\left[\mathrm{Cu}_{2} \mathbf{L} \mathbf{1}\right]^{4+}$ testing the guests reported in Table 1 in dioxane/water solution $20 \% \mathrm{v} / \mathrm{v}$ buffered at $\mathrm{pH} 7$ (HEPES $0.025 \mathrm{M} ; \mathrm{T}=25^{\circ} \mathrm{C}$ ). These studies revealed that $\left[\mathrm{Cu}_{2} \mathbf{L 1}\right]^{4+}$ forms 1:1 adducts with all of the investigated species (Table 1), with 
greatest selectivity for dicarboxylates with a C4 chain (see Figure 3 for succinate). Reduced affinity was found for anions with longer chains, e.g. glutarate (C5) and adipate (C6).

Table 1. Conditional binding constants (as $\log K_{11}$ values) obtained by UV-vis. titrations on $\left[\mathrm{Cu}_{2} \mathbf{L} \mathbf{1}\right]^{4+}$ and $\left[\mathrm{Cu}_{2} \mathbf{L} 2\right]^{4+}$ in dioxane/water solution $20 \% \mathrm{v} / \mathrm{v}$ and water, respectively, buffered at $\mathrm{pH} 7$ by HEPES $0.025 \mathrm{M}\left(\mathrm{T} 25^{\circ} \mathrm{C}\right)$. Standard deviations are shown in parentheses. Titration data were processed with the Hyperquad package. ${ }^{4}$ See S.I. for details.

\begin{tabular}{|c|c|c|}
\hline anionic guest & $\log K_{11}\left[\mathrm{Cu}_{2} \mathbf{L 1}\right]^{4+}$ & $\log _{11}\left[\mathrm{Cu}_{2} \mathbf{L} 2\right]^{4+}$ \\
\hline succinate & $5.60(3)$ & 56 \\
\hline glutarate & $4.14(3)$ & $5.39(1)$ \\
\hline adipate & $3.47(1)$ & $2.58(1)$ \\
\hline isophthalate & $4.98(4)$ & $>6$ \\
\hline fumarate & $5.76(2)$ & $>6$ \\
\hline maleate & $3.65(5)$ & $2.78(1)$ \\
\hline
\end{tabular}
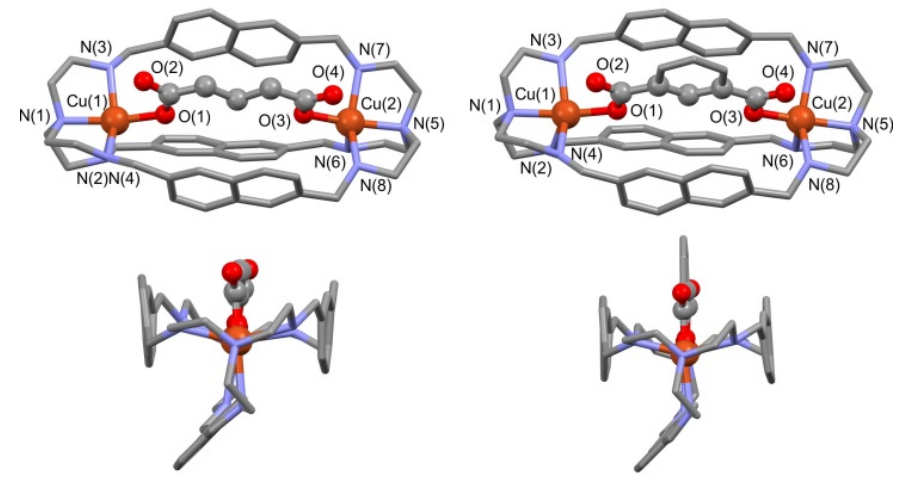

Figure 4. Simplified sketches of the $\left[\mathrm{Cu}_{2} \mathbf{L} 2 \text { (glut) }\right]^{2+}$ molecular cation (left top and left bottom) and of one of the three similar but not symmetrically equivalent $\left[\mathrm{Cu}_{2} \mathbf{L} 2 \text { (isoph) }\right]^{2+}$ molecular cations (right top and right bottom; hydrogen atoms omitted for clarity). Atom names are reported only for $\mathrm{Cu}$, $\mathrm{N}$, and $\mathrm{O}$ atom sites.

Further insight into the binding of dicarboxylates to $\left[\mathrm{Cu}_{2} \mathbf{L 1}\right]^{4+}$ was gained from comparison with UV-vis. titration results obtained on the related model complex $\left[\mathrm{Cu}_{2} \mathbf{L} 2\right]^{4+}$ in water at pH 7 (HEPES $0.025 \mathrm{M} ; \mathrm{T}=25^{\circ} \mathrm{C}$ ). $\mathbf{L} 2$ is known from the literature to form stable dimetallic complexes with $\mathrm{Zn}(\mathrm{II})$ and $\mathrm{Cu}(\mathrm{II}) .^{45}$ Our UV-vis. studies in neutral aqueous solutions showed that, among dicarboxylates with a C4 chain, fumarate (fum ${ }^{2-}$ ) and succinate $\left(\mathrm{suc}^{2-}\right.$ ) are the privileged guests of $\left[\mathrm{Cu}_{2} \mathbf{L} 2\right]^{4+}$, because of their good fit within the cavity. This result is consistent with the crystal structures of $\left[\mathrm{Cu}_{2} \mathbf{L} 2 \text { (suc) }\right]^{2+}$ and $\left[\mathrm{Cu}_{2} \mathbf{L} 2 \text { (fum) }\right]^{2+}$ reported by Lu et al.. ${ }^{45}$

However, also glutarate and isophthalate (i.e. glut ${ }^{2-}$ and isoph ${ }^{2-}$, respectively) form stable $1: 1$ complexes with $\left[\mathrm{Cu}_{2} \mathbf{L} 2\right]^{4+}$, as is shown by our results in both solution and solid state. In particular, X-ray crystal structures of $\left[\mathrm{Cu}_{2} \mathbf{L} 2 \text { (glut) }\right]^{2+}$ and $\left[\mathrm{Cu}_{2} \mathbf{L} 2\left(\mathrm{isoph}^{2+}\right]^{2+}\right.$ show that both anionic guests bridge the two metal centers and reside in the cavity of the cryptate, generating cradle-like arrangements (Figure 4). These complexes are similar to those observed for fumarate and succinate. Given the longer backbones of glutarate and isophthalate ions, the $\mathrm{Cu}(\mathrm{II}) \cdots \mathrm{Cu}(\mathrm{II})$ separation increases from 8.77(1) $\AA$ in $\left[\mathrm{Cu}_{2} \mathbf{L} 2(\mathrm{suc})\right]^{2+}$ and $\left[\mathrm{Cu}_{2} \mathbf{L} 2 \text { (fum) }\right]^{2+}$ molecular cations to $8.95(1) \AA$ in $\left[\mathrm{Cu}_{2} \mathbf{L} 2 \text { (glut) }\right]^{2+}$ molecular cation and to 8.92(1), 8.81(1), 8.89(1) $\AA$ in the three symmetrically independent $\left[\mathrm{Cu}_{2} \mathbf{L} 2(\text { isoph) }]^{2+}\right.$ molecular cations originating in the solid state (see S.I).

The binding of suc ${ }^{2-}$ to the lipophilic azacryptate $\left[\mathrm{Cu}_{2} \mathbf{L 1}\right]^{4+}$, with the formation of the $\left[\mathrm{Cu}_{2} \mathbf{L} \mathbf{1}(\mathrm{suc})\right]^{2+}$ adduct, was confirmed by HRMSESI spectroscopy in an acetonitrile solution of $\left[\mathrm{Cu}_{2} \mathbf{L 1}\right]^{4+}$ treated with 1 eqv. aqueous $\mathrm{Na}_{2}$ suc. The HRMS-ESI spectrum (see S.I.) displays a peak at $796.4592 \mathrm{~m} / \mathrm{z}$, attributable to the doubly charged ion $\left[\mathrm{Cu}_{2} \mathbf{L 1} \text { (suc) }\right]^{2+}$.

Given its high affinity for polycarboxylate guests, we tested the cage-like complex $\left[\mathrm{Cu}_{2} \mathbf{L} \mathbf{1}\right]^{4+}$ as a potential extractant of dicarboxylates from neutral water into an immiscible organic solvent, i.e. dichloromethane. The stability of the $\left[\mathrm{Cu}_{2} \mathbf{L} \mathbf{1} \text { (suc) }\right]^{2+}$ adduct in the chosen solvent was first verified by UV-vis. titration of $\left[\mathrm{Cu}_{2} \mathbf{L 1}\right]^{4+}(30 \mu \mathrm{M})$ with $[\mathrm{TBA}]_{2}$ Suc in dichloromethane (path length $10 \mathrm{~cm}$; $\mathrm{T}=25^{\circ} \mathrm{C}$ ). This study confirmed the high affinity of suc $^{2-}$ for the azacryptate and the formation of a receptor:anion adduct, with a 1:1 stoichiometry (see S.I.).

We then performed liquid-liquid extraction experiments (Figure 5). A $0.20 \mathrm{mM}$ solution of $\left[\mathrm{Cu}_{2} \mathbf{L 1}\right]^{4+}$ in dichloromethane was stirred for 10 minutes in contact with an aqueous solution of $1 \mathrm{mM} \mathrm{H}_{2} \mathrm{Suc}$ in HEPES $0.050 \mathrm{M}$ at pH 7. The successful extraction of $\mathrm{H}_{2}$ suc from water was demonstrated by recording UV-vis. spectra of the organic phase before and after mixing. Notably, the final spectrum of the dichloromethane phase displayed the same changes in the $d-d$ bands of the $\left[\mathrm{Cu}_{2} \mathbf{L} \mathbf{1}\right]^{4+}$ complex as those found upon titration of the azacryptate with $[\mathrm{TBA}]_{2}$ suc in this medium. This result indicates that succinate is successfully transferred from neutral water to dichloromethane, where it is stabilized by complexation with $\left[\mathrm{Cu}_{2} \mathbf{L 1}\right]^{4+}$. 
These initial tests were then followed by quantitative extraction experiments, in which the suc ${ }^{2-}$ concentration in the aqueous layer was monitored by HPLC-UV. These experiments (see S.I. for experimental details) again employed $0.20 \mathrm{mM}^{\mathrm{m}}$ solutions of $\left[\mathrm{Cu}_{2} \mathbf{L} \mathbf{1}\right]^{4+}$ in dichloromethane and $1.0 \mathrm{mM}$ solutions (i.e. 5-fold excess vs. $\left[\mathrm{Cu}_{2} \mathbf{L 1}\right]^{4+}$ ) of $\mathrm{H}_{2} \mathrm{Suc}$ in HEPES $0.050 \mathrm{M}$ at $\mathrm{pH} 7$.

Seven extraction experiments were performed independently over non-consecutive days. HPLC-UV analyses indicated that suc ${ }^{2-}$ was $^{-}$ effectively extracted into the organic phase only in the presence of the azacryptate. The measured average extraction yield was $20 \pm 4 \%$ $(n=7, \alpha 0.05)$, calculated with respect to the initial concentration of $\operatorname{suc}^{2-}$ in the aqueous phase (see S.I. for details). These results indicate that $\mathrm{suc}^{2-}$ is quantitatively extracted into dichloromethane by the cage.

These findings were corroborated by additional trials showing that succinate dianion does not measurably enter the organic phase without complexation by $\left[\mathrm{Cu}_{2} \mathbf{L 1}\right]^{4+}$ : the organic phase was evaporated to dryness after extraction in the absence of cryptand. Chromatographic analysis of the residue, reconstituted with $1 \mathrm{~mL} \mathrm{0.050} \mathrm{M} \mathrm{HEPES} \mathrm{buffer,} \mathrm{showed} \mathrm{an} \mathrm{undetectable} \mathrm{concentration} \mathrm{of} \mathrm{suc}{ }^{2-}$.

It is noteworthy that the experimental value of extraction yield (20\%) as determined by HPLC-UV is in full agreement with the data obtained by UV-vis spectroscopy (i.e. by measuring the spectrum of the $\left[\mathrm{Cu}_{2} \mathbf{L} \mathbf{1}\right]^{4+}$ in the organic phase before and after extraction). Importantly, this yield corresponds to the theoretical maximum extraction yield assuming that suc ${ }^{2-}$ is extracted by complexation of the cage in a 1:1 molar ratio.

In conclusion, we demonstrate that lipophilic cage-like complexes can be successfully applied in the extraction of highly hydrated polyanionic species from water. The quantitative extraction of a dicarboxylate anion (i.e. succinate) was achieved here by employing a suitable lipophilic azacryptate, capable of stabilizing the polyanion in dichloromethane through encapsulation in the cavity. Given the relevance of polycarboxylates as normal metabolites and pathological oncometabolites, as well as industrial waste products, our results open new possibilities for research and application in selective recognition, trapping and extraction of target polycarboxylates..

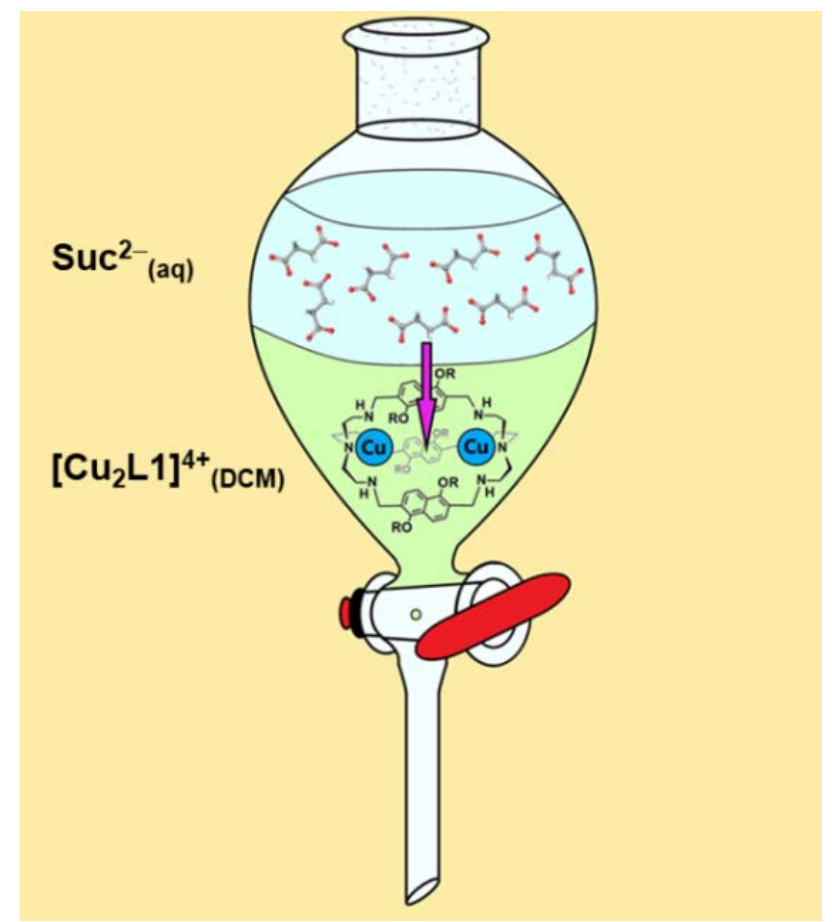

Figure 5. Quantitative extraction of $\operatorname{suc}^{2-}$ from an aqueous solution, buffered at $\mathrm{pH} 7$ by HEPES $0.050 \mathrm{M}$, to dichloromethane (DCM) using the [Cu $\left.2 \mathbf{L 1}\right]^{4+}$ complex $(0.20 \mathrm{mM})$ as the extractant.

\section{ASSOCIATED CONTENT}

\section{Supporting Information}

Materials, methods and experimental details. Synthesis and characterization of L1, NMR and HRMS-ESI spectra. Additional material regarding UV-vis. titrations, anion binding studies, potentiometric investigations, extraction experiments.

\section{AUTHOR INFORMATION}

\section{Corresponding Author}

Valeria Amendola, email: amendola@unipv.it

\section{ORCID ID:}

Valeria Amendola: 0000-0001-5219-6074

Massimo Boiocchi: 0000-0002-4991-145X

Sonia La Cognata: 0000-0002-7393-802X

Louis J. Maher III: 0000-0002-5043-6422 
Francesca Merlo: 0000-0003-1769-1760

Riccardo Mobili: 0000-0003-4451-4364

Andrea Speltini: 0000-0002-6924-7170

Teresa Recca: 0000-0002-2000-7846

¥These authors contributed equally. R. Mobili and S. La Cognata synthesized L1 and L2, performed the UV-vis. investigations, the determination of binding constants, performed the extraction experiments and contributed to the preparation of the manuscript; $\mathrm{M}$. Boiocchi and T. Recca performed X-ray diffraction and NMR studies, respectively. F. Merlo and A. Speltini were involved in the quantification of the succinate anion by HPLC-UV; L. Maher III contributed to writing.

\section{Notes}

The authors declare no competing financial interests.

\section{ACKNOWLEDGMENTS}

Clelia Cazzola is acknowledged for her contribution in the UV-vis. titrations of $\left[\mathrm{Cu}_{2} \mathbf{L} 2\right]^{4+}$ with anions. The Laboratorio Biochimica, Biotecnologie e Diagnostica Avanzata, Fondazione IRCCS Policlinico San Matteo (Pavia, Italy) are gratefully thanked for HRMS measurements.

\section{REFERENCES}

(1) (a) Bowman-James, K.; Bianchi, A.; García-Espana, E. Eds. Anion Coordination Chemistry, John Wiley \& Sons, New York, 2012; (b) Teresa Albelda, M.; Frías, J. C.; García-España, E.; Schneider, H. J. Supramolecular Complexation for Environmental Control. Chem. Soc. Rev. 2012, 41, 3859-3877.

(2) (a) Her, Y. F.; Maher, L. J. Succinate Dehydrogenase Loss in Familial Paraganglioma: Biochemistry, Genetics, and Epigenetics. Int. J. Endocrinol. 2015, 296167; (b) Zhao, T.; Mu, X.; You, Q. Succinate: An Initiator in Tumorigenesis and Progression, Oncotarget 2017, 8(32), 53819-53828.

(3) Tretter, L.; Patocs, A.; Chinopoulos, C. Succinate, an Intermediate in Metabolism, Signal Transduction, ROS, Hypoxia, and Tumorigenesis. Biochim. Biophys. Acta - Bioenerg. 2016, 1857 (8), 1086-1101.

(4) Hosseini, M. W.; Lehn, J. -M. Anion Coreceptor Molecules. Linear Molecular Recognition in the Selective Binding of Dicarboxylate Substrates by Ditopic Polyammonium Macrocycles. Helv. Chim. Acta 1986, 69 (3), 587-603.

(5) Mateus, P.; Delgado, R.; André, V.; Duarte, M. T. Dicarboxylate Recognition Properties of a Dinuclear Copper(II) Cryptate. Inorg. Chem. 2015, 54 (1), 229-240.

(6) Wang, Q. Q.; Day, V. W.; Bowman-James, K. Tunable, Shape-Shifting Capsule for Dicarboxylates. Chem. Sci. 2011, 2 (9), $1735-1738$.

(7) Curiel, D.; Más-Montoya, M.; Sánchez, G. Complexation and Sensing of Dicarboxylate Anions and Dicarboxylic Acids. Coord. Chem. Rev. 2015, 284, 19-66.

(8) Santos, M. M.; Marques, I.; Carvalho, S.; Moiteiro, C.; Félix, V. Recognition of Bio-Relevant Dicarboxylate Anions by an Azacalix[2]Arene[2]Triazine Derivative Decorated with Urea Moieties. Org. Biomol. Chem. 2015, 13 (10), 3070-3085.

(9) Lehn, J. M.; Méric, R.; Vigneron, J. P.; Bkouche-Waksman, I.; Pascard, C. Molecular Recognition of Anionic Substrates. Binding of Carboxylates by a Macrobicyclic Coreceptor and Crystal Structure of Its Supramolecular Cryptate with the Terephthalate Dianion. J. Chem. Soc. Chem. Commun. 1991, 2, 62-64.

(10) Alibrandi, G.; Amendola, V.; Bergamaschi, G.; Fabbrizzi, L.; Licchelli, M. Bistren Cryptands and Cryptates: Versatile Receptors for Anion Inclusion and Recognition in Water. Org. Biomol. Chem. 2015, 3510-3524.

(11) Merli, D.; La Cognata, S.; Balduzzi, F.; Miljkovic, A.; Toma, L.; Amendola, V. A Smart Supramolecular Device for the Detection of t,t-Muconic Acid in Urine†. New J. Chem. 2018, 42 (18), 15460-15465.

(12) Chakraborty, S.; Saha, S.; Lima, L. M. P.; Warzok, U.; Sarkar, S.; Akhuli, B.; Nandi, M.; Bej, S.; Adarsh, N. N.; Schalley, C. A.; et al. PolyamidePolyamine Cryptand as Dicarboxylate Receptor: Dianion Binding Studies in the Solid State, in Solution, and in the Gas Phase. J. Org. Chem. 2017, 82 (19), 10007-10014.

(13) Mateus, P.; Delgado, R.; Brandão, P.; Félix, V. Recognition of Oxalate by a Copper(II) Polyaza Macrobicyclic Complex. Chem. - A Eur. J. 2011, 17 (25), 7020-7031.

(14) Busschaert, N.; Caltagirone, C.; Van Rossom, W.; Gale, P. A. Applications of Supramolecular Anion Recognition. Chem. Rev. 2015, 115(15), 8038-8155.

(15) Gale, P. A.; Caltagirone, C. Fluorescent and Colorimetric Sensors for Anionic Species. Coord. Chem. Rev. 2018, $354,2-27$.

(16) Mills, E.; O’Neill, L. A. J. Succinate: A Metabolic Signal in Inflammation. Trends in Cell Biology. Elsevier Ltd 2014 , pp 313-320.

(17) Grimolizzi, F.; Arranz, L. Multiple Faces of Succinate beyond Metabolism in Blood. Haematologica. 2018, 1586-1592.

(18) Kubik, S. Anion Recognition in Aqueous Media by Cyclopeptides and Other Synthetic Receptors. Acc. Chem. Res. 2017,50 (11), $2870-2878$.

(19) Carnegie, R. S.; Gibb, C. L. D.; Gibb, B. C. Anion Complexation and the Hofmeister Effect. Angew. Chemie - Int. Ed. 2014, 53 (43), 1149811500.

(20) Jagleniec, D.; Dobrzycki, Ł.; Karbarz, M.; Romański, J. Ion-Pair Induced Supramolecular Assembly Formation for Selective Extraction and Sensing of Potassium Sulfate. Chem. Sci. 2019, 10, 9542-9547.

(21) (a) Fabbrizzi, L. Cryptands and Cryptates. World Scientific Publishing Europe Ltd., London; (b) Amendola, V.; Bergamaschi, G.; Miljkovic, A. Azacryptands as Molecular Cages for Anions and Metal Ions. Supramol. Chem. 2018, 30 (4), $236-242$.

(22) Langton, M. J.; Robinson, S. W.; Marques, I.; Félix, V.; Beer, P. D. Halogen Bonding in Water Results in Enhanced Anion Recognition in Acyclic and Rotaxane Hosts. Nat. Chem. 2014, 6 (12), 1039-1043.

(23) Langton, M. J.; Serpell, C. J.; Beer, P. D. Anion Recognition in Water: Recent Advances from a Supramolecular and Macromolecular Perspective. Angew. Chemie - Int. Ed. 2016, 55 (6), 1974-1987.

(24) Evans, N. H.; Beer, P. D. Advances in Anion Supramolecular Chemistry: From Recognition to Chemical Applications. Angew. Chem. - Int. Ed. 2014, 27, 11716-11754.

(25) Aletti, A. B.; Gillen, D. M.; Gunnlaugsson, T. Luminescent/Colorimetric Probes and (Chemo-) Sensors for Detecting Anions Based on Transition and Lanthanide Ion Receptor/Binding Complexes. Coord. Chem. Rev. 2018, 354, 98-120.

(26) Gale, P. A.; Davis, J. T.; Quesada, R. Anion Transport and Supramolecular Medicinal Chemistry. Chem. Soc. Rev. 2017, 2497-2519.

(27) Bowman-James, K. Supramolecular Cages Trap Pesky Anions. Science. 2019, 365(6449), $124-125$. 
(28) Liu, Y.; Zhao, W.; Chen, C. H.; Flood, A. H. Chloride Capture Using a C-H Hydrogen Bonding Cage. Science 2019, 365(6449), 159-161. Lithium Chloride Using Strapped Calix[4]Pyrroles. Angew. Chemie - Int. Ed. 2018, 57 (37), 11924-11928.

(30) He, Q.; Vargas-Zúñiga, G. I.; Kim, S. H.; Kim, S. K.; Sessler, J. L. Macrocycles as Ion Pair Receptors. Chem. Rev. 2019,119 (17), $9753-9835$.

(31) He, Q.; Zhang, Z.; Brewster, J. T.; Lynch, V. M.; Kim, S. K.; Sessler, J. L. Hemispherand-Strapped Calix[4]Pyrrole: An Ion-Pair Receptor for the Recognition and Extraction of Lithium Nitrite. J. Am. Chem. Soc. 2016, 138 (31), 9779-9782.

(32) Kuk Kim, S.; Lee, J.; J. Williams, N.; M. Lynch, V.; P. Hay, B.; A. Moyer, B.; L. Sessler, J. Bipyrrole-Strapped Calix[4]Pyrroles: Strong Anion Receptors That Extract the Sulfate Anion. J. Am. Chem. Soc. 2014, 136 (42), 15079-15085.

(33) Spooner, M. J.; Li, H.; Marques, I.; Costa, P. M. R.; Wu, X.; Howe, E. N. W.; Busschaert, N.; Moore, S. J.; Light, M. E.; Sheppard, D. N.; et al. Fluorinated Synthetic Anion Carriers: Experimental and Computational Insights into Transmembrane Chloride Transport. Chem. Sci. 2019, 10 (7), $1976-1985$.

(34) Wu, X.; Howe, E. N. W.; Gale, P. A. Supramolecular Transmembrane Anion Transport: New Assays and Insights. Acc. Chem. Res. 2018, 51 (8), 1870-1879.

(35) Gale, P. A. From Anion Receptors to Transporters. Acc. Chem. Res. 2011, 44 (3), 216-226.

(36) Jowett, L. A.; Howe, E. N. W.; Wu, X.; Busschaert, N.; Gale, P. A. New Insights into the Anion Transport Selectivity and Mechanism of TrenBased Tris-(Thio)Ureas. Chem. - A Eur. J. 2018, 24 (41), 10475-10487.

(37) Grauwels, G.; Valkenier, H.; Davis, A. P.; Jabin, I.; Bartik, K. Repositioning Chloride Transmembrane Transporters: Transport of Organic Ion Pairs. Angew. Chemie - Int. Ed. 2019, 58 (21), 6921-6925.

(38) Li, H.; Valkenier, H.; Judd, L. W.; Brotherhood, P. R.; Hussain, S.; Cooper, J. A.; Jurček, O.; Sparkes, H. A.; Sheppard, D. N.; Davis, A. P. Efficient, Non-Toxic Anion Transport by Synthetic Carriers in Cells and Epithelia. Nat. Chem. 2016, 8 (1), 24-32.

(39) Eytel, L. M.; Brueckner, A. C.; Lohrman, J. A.; Haley, M. M.; Cheong, P. H. Y.; Johnson, D. W. Conformationally Flexible Arylethynyl Bis-Urea Receptors Bind Disparate Oxoanions with Similar, High Affinities. Chem. Commun. 2018, 54 (94), 13208-13211.

(40) J. Fowler, C.; J. Haverlock, T.; A. Moyer, B.; A. Shriver, J.; E. Gross, D.; Marquez, M.; L. Sessler, J.; Alamgir Hossain, M.; Bowman-James, K. Enhanced Anion Exchange for Selective Sulfate Extraction: Overcoming the Hofmeister Bias. J. Am. Chem. Soc. 2008, 130 (44), $14386-14387$.

(41) Ji, X.; Wu, R.-T.; Long, L.; Guo, C.; M. Khashab, N.; Huang, F.; L. Sessler, J. Physical Removal of Anions from Aqueous Media by Means of a Macrocycle-Containing Polymeric Network. J. Am. Chem. Soc. 2018, 140 (8), 2777-2780.

(42) Baragaña, B.; Blackburn, A. G.; Breccia, P.; Davis, A. P.; De Mendoza, J.; Padrón-Carrillo, J. M.; Prados, P.; Riedner, J.; De Vries, J. G. Enantioselective Transport by a Steroidal Guanidinium Receptor; 2002; Vol. 8.

(43) Urban, C.; Schmuck, C. Active Transport of Amino Acids by a Guanidiniocarbonyl-Pyrrole Receptor. Chem. - A Eur. J. 2010, 16 (31), 95029510.

(44) (a) Gans, P.; Sabatini, A.; Vacca, A. Investigation of Equilibria in Solution. Determination of Equilibrium Constants with the HYPERQUAD Suite of Programs. Talanta 1996, 43, 1793-1802; (b) Thordarson, P. Determining association constants from titration experiments in supramolecular chemistry. Chem. Soc. Rev. 2011, 40, 1305-1323.

(45) Xie, G. Y.; Jiang, L.; Lu, T. B. Discrimination of Cis-Trans Isomers by Dinuclear Metal Cryptates at Physiological PH: Selectivity for Fumarate vs. Maleate. Dalt. Trans. 2013, 42 (39), 14092-14099. 


\section{SUPPLEMENTARY SECTION}

\section{Succinate extraction from water using a cage-like dicopper complex}

Riccardo Mobili, ${ }^{1}$ Sonia La Cognata, ${ }^{1}$ Francesca Merlo ${ }^{1}$, Andrea Speltini ${ }^{2}$, Massimo Boiocchi, ${ }^{3}$ Teresa Recca, ${ }^{3}$ Louis J. Maher III ${ }^{4}$ and Valeria Amendola ${ }^{1 *}$

${ }^{1}$ Department of Chemistry, v.le T. Taramelli 12, Pavia, Italy; ${ }^{2}$ Department of Drug Sciences, via Taramelli 12, Pavia, Italy; ${ }^{3}$ Centro Grandi Strumenti, via A. Bassi 21, Pavia, Italy; ${ }^{4}$ Department of Biochemistry and Molecular Biology, Mayo Clinic, Rochester, MN, USA

* corresponding author: Valeria Amendola, email: amendola@unipv.it 


\section{Index}

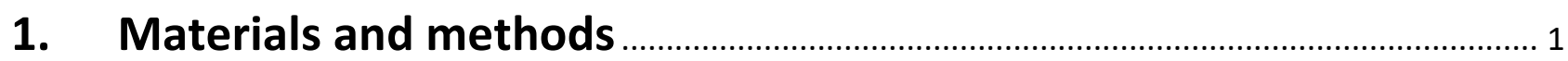

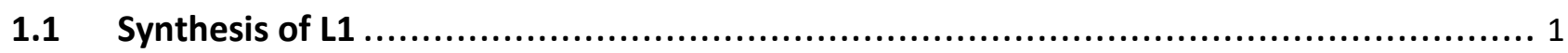

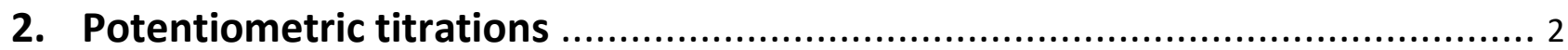

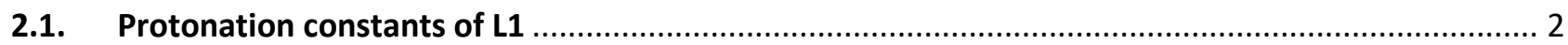

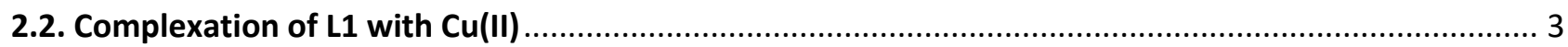

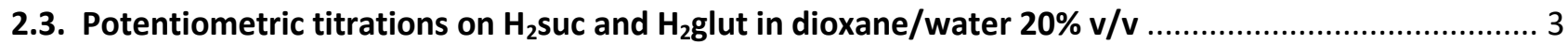

3. Spectrophotometric titrations...................................................... 5

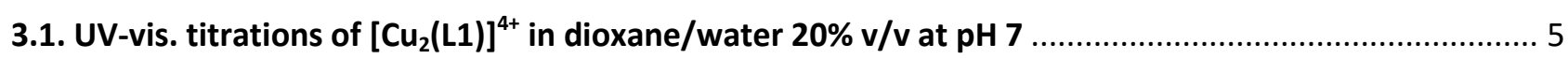

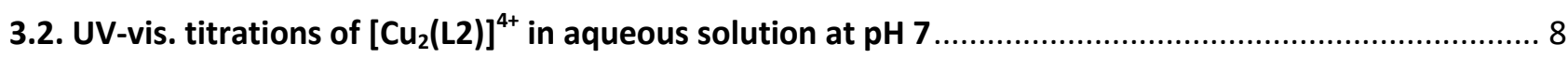

3.3. UV-vis. titration of $\left[\mathrm{Cu}_{2}(\mathrm{L1})\right]^{4+}$ with succinate in dichloromethane .............................................. 11

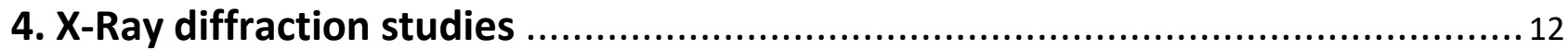

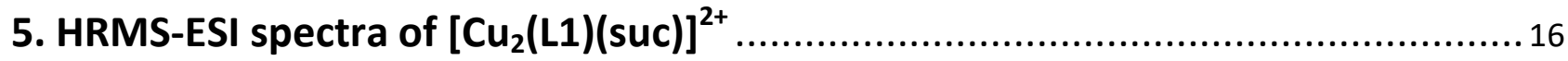

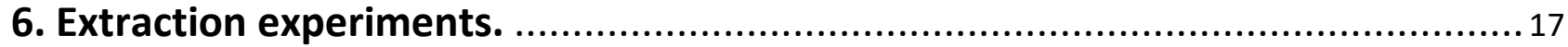

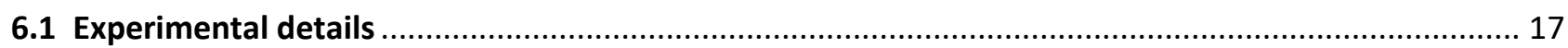

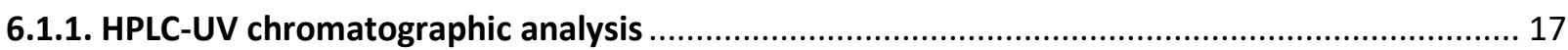

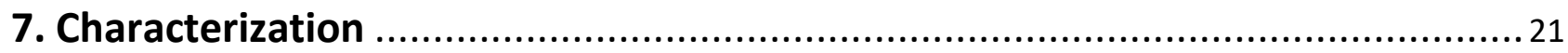

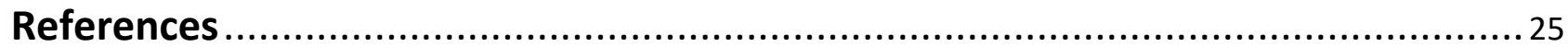




\section{Materials and methods}

All reagents for syntheses were purchased from Sigma-Aldrich and used without further purification. All reactions were performed under dinitrogen. High-resolution mass spectra were recorded on a Thermo Scientific Q Exactive Plus instrument. ${ }^{1} \mathrm{H}$ - and ${ }^{13} \mathrm{C}-\mathrm{NMR}$ spectra were recorded on Bruker AVANCE 400 (operating at $9.37 \mathrm{~T}, 400 \mathrm{MHz}$ ). 1,5-di(hexyloxy)naphthalene2,6-dicarboxaldehyde, $[\mathrm{TBA}]_{2}$ suc and $\mathbf{L} 2$ were synthesized following known procedures. ${ }^{1-3}$

\subsection{Synthesis of L1}<smiles>CCOc1c(C=O)ccc2c(OC)c(C=O)ccc12</smiles>

Chemical Formula: $\mathrm{C}_{24} \mathrm{H}_{32} \mathrm{O}$ Molecular Weight: 384,51

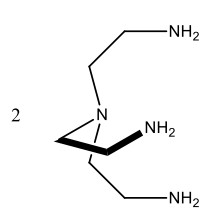

Chemical Formula: $\mathrm{C}_{6} \mathrm{H}_{18} \mathrm{~N}_{4}$ Molecular Weight: 146,23

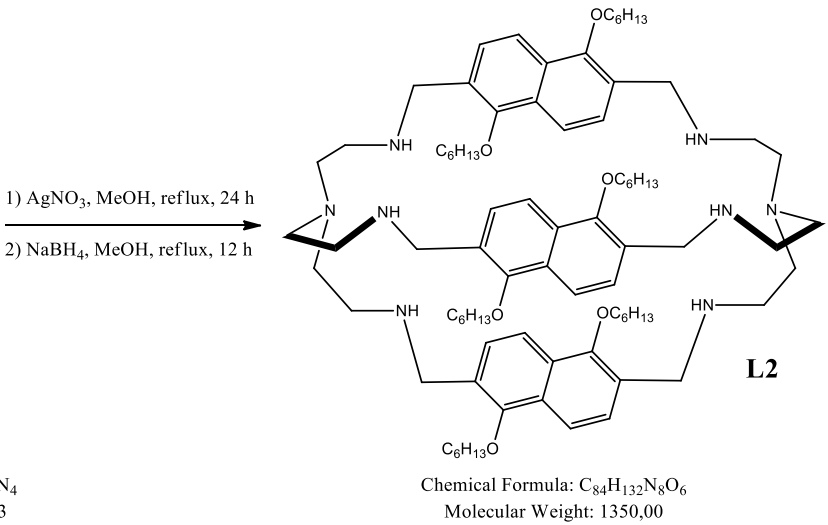

Chemical Formula: $\mathrm{C}_{84} \mathrm{H}_{132} \mathrm{~N}_{8} \mathrm{O}_{6}$
Molecular Weight: 1350,00

A solution of 1,5-di(hexyloxy)naphthalene-2,6-dicarboxaldehyde $(0.12 \mathrm{~g} ; 0.31 \mathrm{mmol} ; 3.0 \mathrm{eqv})$ in dicloromethane $(\mathrm{DCM} ; 10 \mathrm{~mL})$ and $\mathrm{MeOH}(70 \mathrm{~mL})$ was added to a solution of $\mathrm{AgNO}_{3}(0.05 \mathrm{~g}$; $0.31 \mathrm{mmol} ; 3.0 \mathrm{eqv})$ in $\mathrm{MeOH}(70 \mathrm{~mL})$. The reaction mixture was then refluxed under $\mathrm{Ar}$ atmosphere. A solution of tris(2-aminoethyl)amine $(0.03 \mathrm{~mL} ; 0.21 \mathrm{mmol} ; 2.0$ eqv) in $\mathrm{MeOH}(50$ $\mathrm{mL}$ ) was then slowly added dropwise and the reaction was refluxed for 24 hours. The solution containing the polyimine cage compound was then transferred in a round bottom flask and DCM was evaporated under vacuum. The methanol solution was refluxed again and $\mathrm{NaBH}_{4}(3.0 \mathrm{~g})$ was added in small portions in order to reduce both imine bonds and $\mathrm{Ag}^{+}$. After 12 hours the mixture was cooled to room temperature and filtered to eliminate $\mathrm{Ag}^{0}$ particles. The solvent was evaporated under vacuum to give a white solid that was dissolved with brine $(200 \mathrm{~mL})$ and extracted with DCM $(4 \times 50 \mathrm{~mL})$. The collected organic phase was then dried with $\mathrm{Na}_{2} \mathrm{SO}_{4}$. The solvent was evaporated under vacuum to obtain $0.13 \mathrm{~g}$ of a yellowish dense oil. Yield: $91 \%$

H-NMR (400 MHz, d $\left.6_{6}-\mathrm{DMSO}+\mathrm{HNO}_{3}, \mathrm{~T}=80^{\circ} \mathrm{C}\right) \delta: 7.84-7.61\left(6 \mathrm{H}\right.$, naph), $4.44\left(\mathrm{~m}, 12 \mathrm{H}, \mathrm{N}-\mathrm{CH}_{2^{-}}\right.$ naph), 3.91 (m, $\left.12 \mathrm{H}, \mathrm{O}-\mathrm{CH}_{2}-\mathrm{C}\right), 3.20-2.80$ (br. m, $\left.24 \mathrm{H}, \mathrm{N}-\mathrm{CH}_{2} \mathrm{CH}_{2}-\mathrm{N}\right), 1.97$ (m, $12 \mathrm{H}, \mathrm{OCH}_{2}-\mathrm{CH}_{2}-$ C), $1.51-1.27\left(\mathrm{~m}, 36 \mathrm{H}, \mathrm{O}\left(\mathrm{CH}_{2}\right)_{2}-\left(\mathrm{CH}_{2}\right)_{3}-\mathrm{C}\right), 0.91\left(\mathrm{t}, 18 \mathrm{H},-\mathrm{CH}_{3}\right) ;{ }^{13} \mathrm{C}-\mathrm{NMR}\left(100 \mathrm{MHz}, \mathrm{d}_{6}-\mathrm{DMSO}\right.$, $\mathrm{T}=298 \mathrm{~K}) \delta$ : 154.02, 129.16, 126.89, 122.22, 118.91, 76.32, 51.07, 45.68, 45.26, 31.78, 30.29, $25.53,22.61,14.40$.

HRMS-ESI $(\mathrm{MeOH}) \mathrm{m} / z$ : $\left[\mathrm{M}+\mathrm{H}^{+}\right]^{+}$calculated for $\mathrm{C}_{84} \mathrm{H}_{132} \mathrm{~N}_{8} \mathrm{O}_{6}, 1350.0348$, found 1350.0529; $\left[\mathrm{M}+2 \mathrm{H}^{+}\right]^{2+}$ calculated 675.5208 , found $675.5296 ;\left[\mathrm{M}+3 \mathrm{H}^{+}\right]^{3+}$ calculated 450.6829 , found 450.6889 . 


\section{Potentiometric titrations}

Protonation constants of ligand $\mathbf{L 1}$ were determined in dioxane/water (20\% v/v) mixture, 0.05 $\mathrm{M}$ in [TBA] $\mathrm{NO}_{3}$. In a typical experiment, $15 \mathrm{~mL}$ of a $4 \times 10^{-4} \mathrm{M}$ ligand solution was treated with an excess of $\mathrm{HNO}_{3} 1.0 \mathrm{M}$. Titrations were performed by addition of $10 \mu \mathrm{L}$ aliquots of carbonate-free standard 0.1 M NaOH, recording 80-100 points for each titration. Complexation constants were determined by performing a potentiometric titration experiment, working in the presence of 2 eqv. of $\mathrm{Cu}\left(\mathrm{NO}_{3}\right)_{2}$. Prior to each potentiometric titration, the standard electrochemical potential $\left(\mathrm{E}^{\circ}\right)$ of the glass electrode was determined in the dioxane/water mixture, by a titration experiment according to the Gran method ${ }^{4}$. Protonation and complexation titration data (emf $v s . \mathrm{mL}$ of $\mathrm{NaOH}$ ) were processed with the Hyperquad package ${ }^{5}$ to estimate the equilibrium constants.

The same procedure was followed for the determination of the protonation constants of succinic and glutaric acids in dioxane/water $(20 \% \mathrm{v} / \mathrm{v})$ mixture, $0.05 \mathrm{M}$ in $[\mathrm{TBA}] \mathrm{NO}_{3}$. In a typical experiment, $15 \mathrm{~mL}$ of a $1 \times 10^{-3} \mathrm{M}$ ligand solution were treated with an excess of a $1.0 \mathrm{M} \mathrm{HNO}_{3}$ standard solution.

$\mathrm{pH}$-spectrophotometric titrations were also performed on solutions of the dicopper(II) azacryptate $4 \times 10^{-4} \mathrm{M}$ in dioxane/water $(20 \% \mathrm{v} / \mathrm{v})$ mixture $\left(0.05 \mathrm{M}\right.$ [TBA] $\left.\mathrm{NO}_{3}, 25^{\circ} \mathrm{C}\right)$. In a typical titration, aliquots of carbonate-free standard $0.1 \mathrm{M} \mathrm{NaOH}$ were added to the solution of the azacryptate, both the electrochemical potential and the UV-vis. spectrum of the solution were recorded after each addition. Prior to the titration, the standard electrochemical potential $\left(\mathrm{E}^{\circ}\right)$ was determined by the Gran method.

\subsection{Protonation constants of $\mathbf{L} \mathbf{1}$}

Best fits of the potentiometric titration profiles were obtained by assuming the presence of six protonated species at the equilibrium over the course of the potentiometric experiment. The calculated protonation constants (Table $\mathrm{S} 1$ ) allowed calculation of the species distribution diagram (as \% abundance with respect to $\mathbf{L 1} v s . \mathrm{pH}$ ) reported in Figure $\mathrm{S} 1$.

Table S1. Protonation equilibria and the corresponding constants for $\mathbf{L 1}$ (L in the Table) in dioxane/water 20\% v/v $\left(\mathrm{T}=25^{\circ} \mathrm{C}\right)$. Standard deviation in parentheses.

\begin{tabular}{lc}
\hline Equilibria & $\mathbf{L o g} \boldsymbol{\beta}$ \\
\hline $\mathbf{L 1}+\mathrm{H}^{+} \rightleftarrows \mathbf{L} 1 \mathrm{H}^{+}$ & $9.03(8)$ \\
$\mathbf{L 1}+2 \mathrm{H}^{+} \rightleftarrows \mathbf{L} 1 \mathrm{H}_{2}{ }^{2+}$ & $17.74(4)$ \\
$\mathbf{L 1}+3 \mathrm{H}^{+} \rightleftarrows \mathbf{L 1 H}_{3}{ }^{3+}$ & $25.72(6)$ \\
$\mathbf{L 1}+4 \mathrm{H}^{+} \rightleftarrows \mathbf{L 1 H}_{4}{ }^{4+}$ & $32.66(6)$ \\
$\mathbf{L 1}+5 \mathrm{H}^{+} \rightleftarrows \mathbf{L 1 H}_{5}{ }^{5+}$ & $39.25(6)$ \\
$\mathbf{L 1}+6 \mathrm{H}^{+} \rightleftarrows \mathbf{L 1 H}_{6}{ }^{6+}$ & $44.50(7)$
\end{tabular}




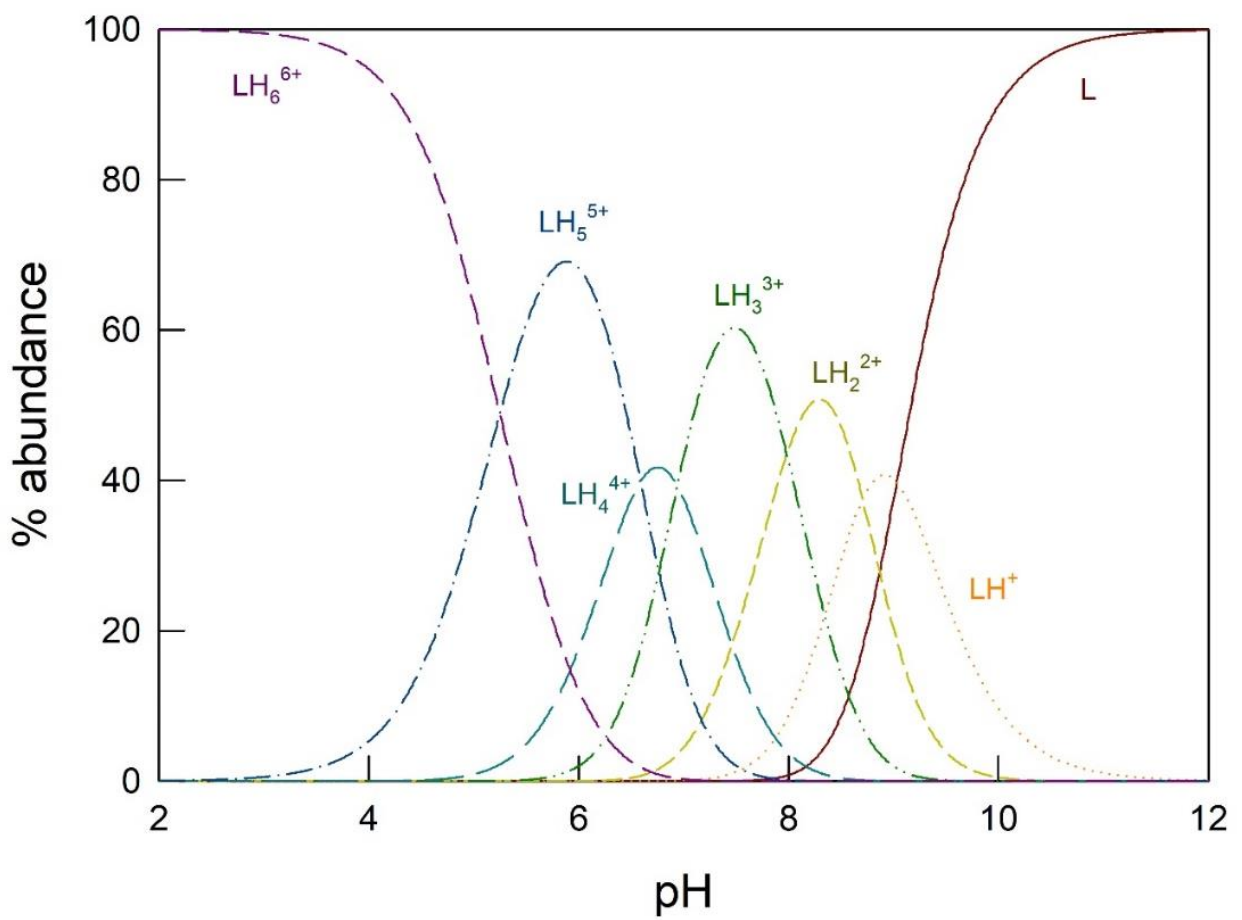

Figure S1. Distribution diagram of species present at equilibrium over the course of the potentiometric titration of L1 (4 $\left.\times 10^{-4} \mathrm{M}\right)$, noted as $\mathrm{L}$ in the figure, with standard $\mathrm{NaOH}$ in dioxane/water $(20 \% \mathrm{v} / \mathrm{v})\left(\mathrm{T}=25^{\circ} \mathrm{C}\right)$.

\subsection{Complexation of $\mathrm{L} 1$ with $\mathrm{Cu}(\mathrm{II})$}

Best fitting was obtained by assuming the formation of the following complex species over the course of the titration: $\left[\mathrm{Cu}\left(\mathbf{L} 1 H_{3}\right)\right]^{5+},\left[\mathrm{Cu}_{2}(\mathbf{L 1})\right]^{4+},\left[\mathrm{Cu}_{2}(\mathbf{L 1}) \mathrm{OH}\right]^{3+}, \quad\left[\mathrm{Cu}_{2}(\mathbf{L 1})(\mathrm{OH})_{2}\right]^{2+}$. The corresponding cumulative constants $($ as $\log \beta$ ) are shown in Table $\mathrm{S} 2$. The distribution diagram (as $\%$ abundance $v$ s. $\mathrm{pH}$ is reported in the main text, see Figure 2.

Table S2. Complexation constants for $\mathbf{L 1}$ with $\mathrm{Cu}(\mathrm{II})$ in dioxane/water $20 \% \mathrm{v} / \mathrm{v}\left(\mathrm{T}=25{ }^{\circ} \mathrm{C}\right)$. Standard deviation in parentheses.

\begin{tabular}{lc}
\hline Equilibria & Log $\boldsymbol{\beta}$ \\
\hline $\mathbf{L 1}+\mathrm{Cu}^{2+}+3 \mathrm{H}^{+} \rightleftarrows\left[\mathrm{Cu}\left(\mathbf{L} 1 \mathrm{H}_{3}\right)\right]^{5+}$ & $35.37(3)$ \\
$\mathbf{L 1}+2 \mathrm{Cu}^{2+} \rightleftarrows\left[\mathrm{Cu}_{2}(\mathbf{L} \mathbf{1})\right]^{4+}$ & $24.60(7)$ \\
$\mathbf{L} \mathbf{1}+2 \mathrm{Cu}^{2+}+\mathrm{H}_{2} \mathrm{O} \rightleftarrows\left[\mathrm{Cu}_{2}(\mathbf{L 1}) \mathrm{OH}\right]^{3+}+\mathrm{H}^{+}$ & $12.4(1)$ \\
$\mathbf{L 1}+2 \mathrm{Cu}^{2+}+2 \mathrm{H}_{2} \mathrm{O} \rightleftarrows\left[\mathrm{Cu}_{2}(\mathbf{L 1})(\mathrm{OH})_{2}\right]^{2+}+2 \mathrm{H}^{+}$ & $1.8(1)$ \\
\hline
\end{tabular}

\subsection{Potentiometric titrations on $\mathrm{H}_{2} \mathrm{suc}$ and $\mathrm{H}_{2}$ glut in dioxane/water $20 \% \mathrm{v} / \mathrm{v}$}

Potentiometric titrations were also performed on two representative dicarboxylic acids, $\mathrm{H}_{2}$ suc and $\mathrm{H}_{2}$ glut, in order to determine their $\mathrm{p} K_{a}$ values in dioxane/water mixture $20 \% \mathrm{v} / \mathrm{v}(0.05 \mathrm{M}$ [TBA] $\mathrm{NO}_{3}, 25^{\circ} \mathrm{C}$ ). In pure water at $\mathrm{pH} 7$, both acids are largely deprotonated, with $\mathrm{p} K_{a 1}$ and $\mathrm{pK}_{a 2}$ : 
4.21 and 5.41 for $\mathrm{H}_{2}$ suc; 4.34 and 5.22 at $25^{\circ} \mathrm{C}$ for $\mathrm{H}_{2}$ glut. ${ }^{6}$ In the chosen mixture, deprotonation to form the dicarboxylate anion is significantly shifted toward basic $\mathrm{pH}$ values for both $\mathrm{H}_{2}$ suc and $\mathrm{H}_{2}$ glut. The potentiometric titrations allowed estimation of $\mathrm{p} K_{a}$ values, which were found to be $\mathrm{p} K_{a 1}=6.89(4)$ and $\mathrm{pK}_{a 2}=8.74(6)$ for $\mathrm{H}_{2}$ suc, $\mathrm{p} K_{a 1}=7.55(5)$ and $\mathrm{pK}_{a 2}=8.36(7)$ for $\mathrm{H}_{2}$ glut. The corresponding distribution diagram of the species, as \% abundance vs. $\mathrm{pH}$, are reported in Figures S2-S3.

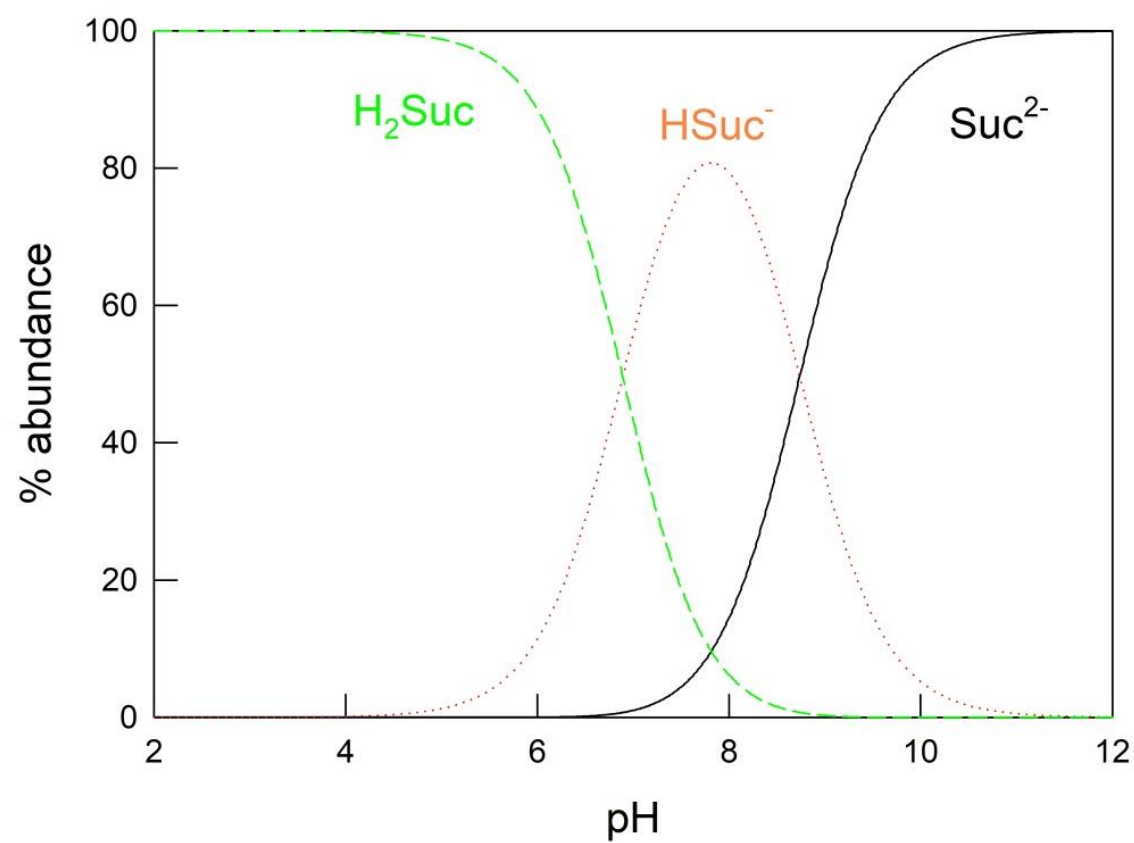

Figure S2. Distribution diagram of the species present at the equilibrium over the course of the potentiometric titration of $\mathrm{H}_{2}$ suc $\left(1 \times 10^{-3} \mathrm{M}\right)$ with standard $\mathrm{NaOH}$ in dioxane/water $20 \% \mathrm{v} / \mathrm{v}\left(\mathrm{T}=25^{\circ} \mathrm{C}\right)$.

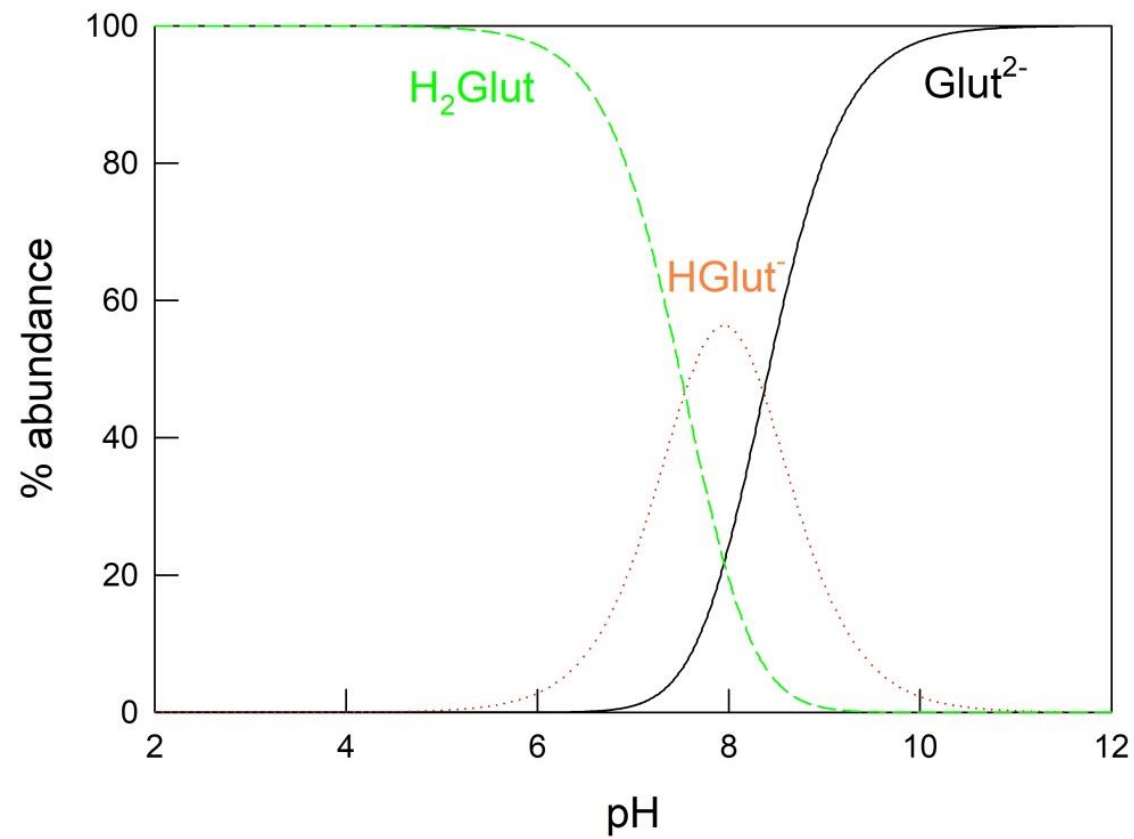

Figure S3. Distribution diagram of the species present at the equilibrium over the course of the potentiometric titration of $\mathrm{H}_{2}$ glut $\left(1 \times 10^{-3} \mathrm{M}\right)$ with standard $\mathrm{NaOH}$ in dioxane/water $20 \% \mathrm{v} / \mathrm{v}\left(\mathrm{T}=25^{\circ} \mathrm{C}\right)$. 


\section{Spectrophotometric titrations}

UV-vis. spectra were collected using a Varian Cary 50 SCAN spectrophotometer, with quartz cuvettes of the appropriate path length $(1$ or $10 \mathrm{~cm})$ at $25.0 \pm 0.1^{\circ} \mathrm{C}$. Solvents were dried by common methods. In a typical experiment, a concentrated solution of the dicopper(II) azacryptate in DMSO was diluted with buffer at $\mathrm{pH} 7$, i.e. 0.025M HEPES in either dioxane/water $(20 \% \mathrm{v} / \mathrm{v})$ for $\left[\mathrm{Cu}_{2}(\mathbf{L 1})\right]^{4+}$ or pure water for $\left[\mathrm{Cu}_{2}(\mathbf{L 2})\right]^{4+}$ : the final concentration of the azacryptate ranged between $50-500 \mu \mathrm{M}$. The buffered solution of the azacryptate was then titrated with a standard solution of either the chosen dicarboxylic acid or the corresponding disodium salt, in the case of phthalates. After each addition of the titrant solution, the UV-vis. spectrum was recorded. It has to be noticed that, with terephthalate and phthalate anions, the formation of a precipitate over the course of the titration prevented us to safely determine the association constants. The concentration of the azacryptate solution was chosen on the basis of the p-parameter ( $p=$ [concentration of the azacryptate:anion adduct]/[maximum possible concentration of the azacryptate:anion adduct]), which should range between 0.2 and $0.8 .^{7-8}$ Titration data were processed with the Hyperquad package 5 to estimate equilibrium constants. In some cases, even working with very dilute solutions of the azacryptate, the curvature of the titration profile was too sharp to allow a safe calculation of the binding constant. In these cases, the distribution diagrams were traced assuming an estimated value of the constant (obtained using Hyperquad package).

\subsection{UV-vis. titrations of $\left[\mathrm{Cu}_{2}(\mathrm{~L} 1)\right]^{4+}$ in dioxane/water $20 \% \mathrm{v} / \mathrm{v}$ at $\mathrm{pH} 7$}
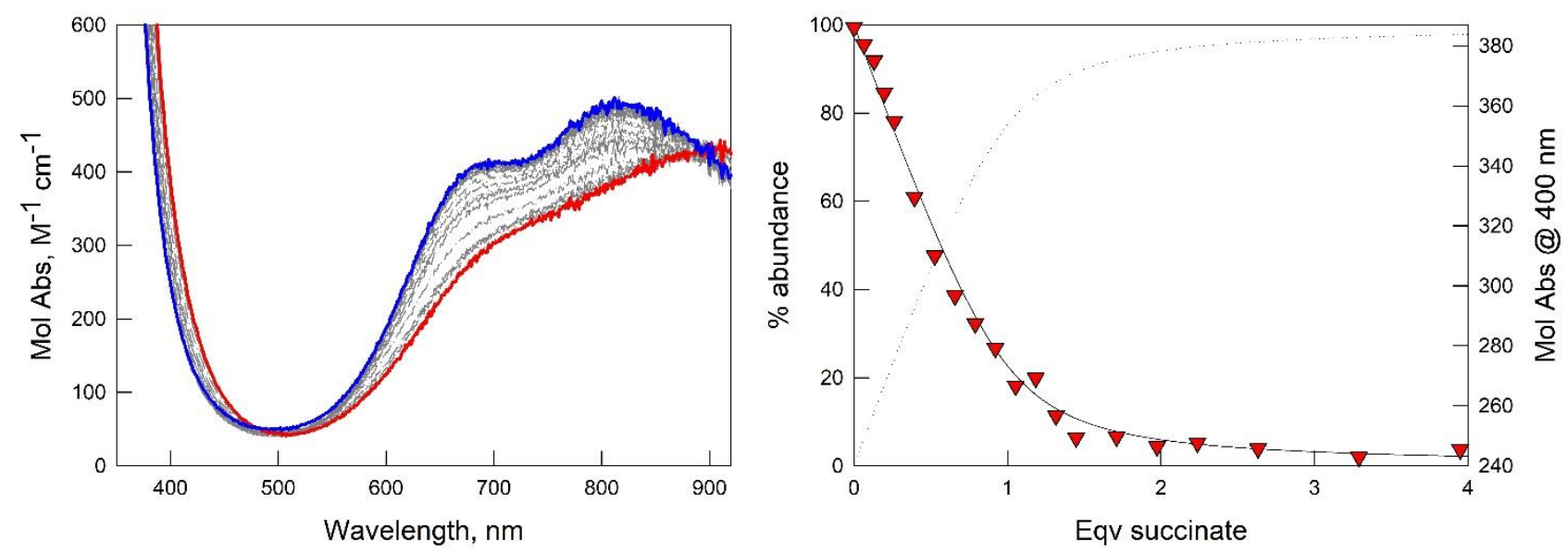

Figure S4. Left: UV-vis. spectra taken upon titration of $\left[\mathrm{Cu}_{2}(\mathbf{L 1})\right]^{4+} 50 \mu \mathrm{M}$ with succinate $12.5 \mathrm{mM}$ in dioxane/water $20 \% \mathrm{v} / \mathrm{v}$ at $\mathrm{pH} 7$ (HEPES $0.025 \mathrm{M}$, path length $10 \mathrm{~cm}$ ). The red and blue lines represent the spectra at 0 and 5 eqv. of the added anion, respectively. Right: titration profile at $400 \mathrm{~nm}$ (red triangles) with superimposed distribution diagram of the species $\left[\mathrm{Cu}_{2}(\mathbf{L 1})\right]^{4+}$ (solid line) and $\left[\mathrm{Cu}_{2}(\mathbf{L 1})(\mathrm{suc})\right]^{2+}$ vs. equivalents of the added guest (dotted line), calculated for $\log K_{11}=5.60(3)$. 

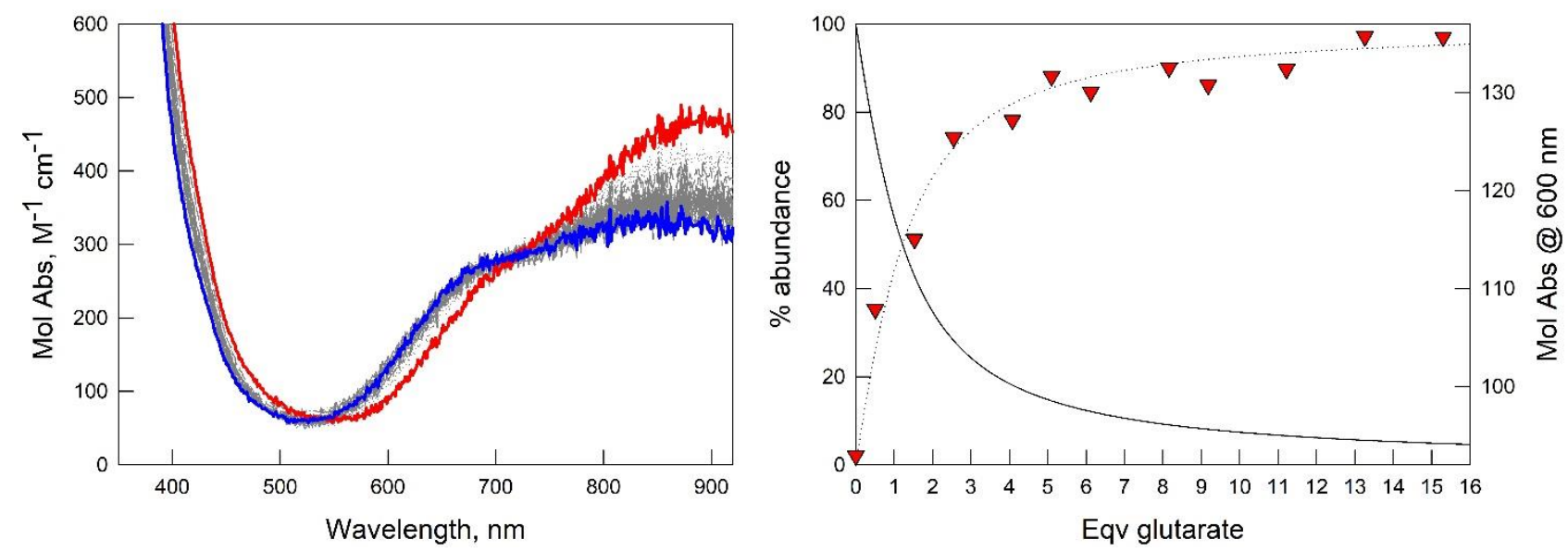

Figure S5. Left: UV-vis. spectra taken upon titration of $\left[\mathrm{Cu}_{2}(\mathbf{L 1})\right]^{4+} 0.20 \mathrm{mM}$ with glutarate $10 \mathrm{mM}$ in dioxane/water $20 \% \mathrm{v} / \mathrm{v}$ at $\mathrm{pH} 7$ (HEPES $0.025 \mathrm{M}$, path length $1 \mathrm{~cm}$ ). The red and blue lines represent the spectra at 0 and 50 eqv. of the added anion, respectively. Right: titration profile at $600 \mathrm{~nm}$ (red triangles) with the superimposed distribution diagram of the species $\left[\mathrm{Cu}_{2}(\mathbf{L 1})\right]^{4+}$ (solid line) and $\left[\mathrm{Cu}_{2}(\mathbf{L 1})(\mathrm{glut})\right]^{2+}$ (dotted line) vs. equivalents of the added guest, calculated for $\log K_{1 I}=4.14(3)$.
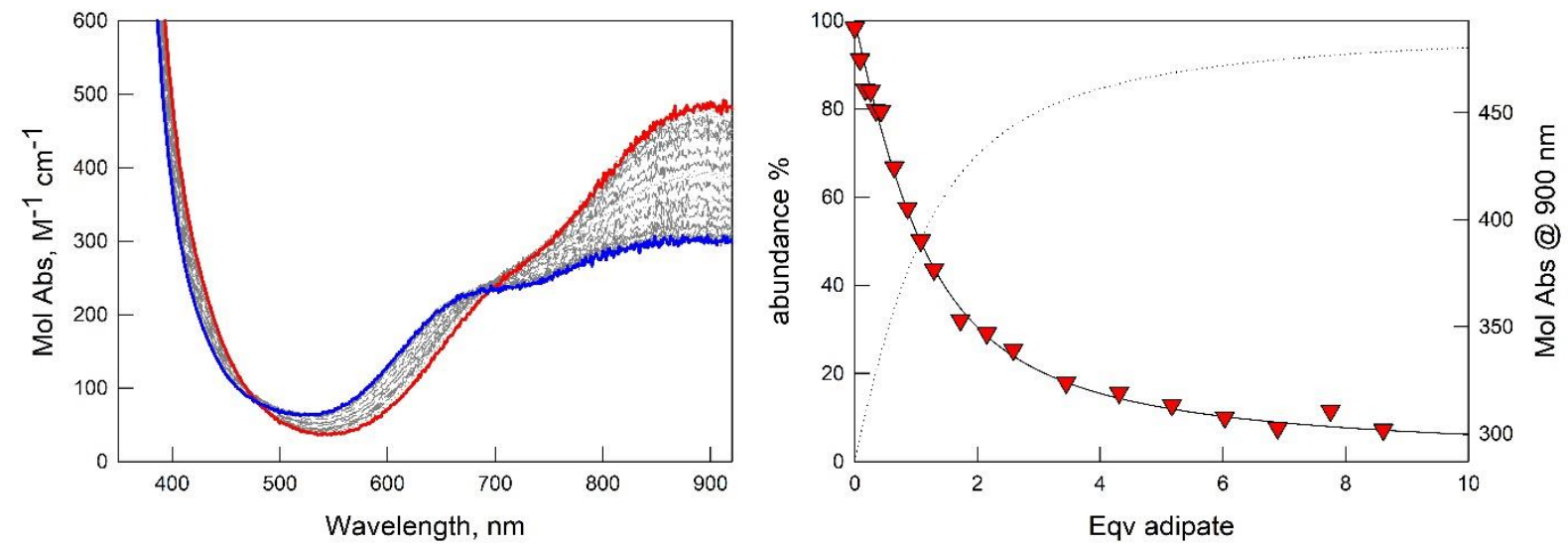

Figure S6. Left: UV-vis. spectra taken upon titration of $\left[\mathrm{Cu}_{2}(\mathbf{L 1})\right]^{4+} 0.55 \mathrm{mM}$ with adipate $0.10 \mathrm{M}$ in dioxane/water $20 \% \mathrm{v} / \mathrm{v}$ at pH 7 (HEPES $0.025 \mathrm{M}$, path length $1 \mathrm{~cm}$ ). The red and blue lines represent the spectra at 0 and 8.5 eqv. of the added anion, respectively. Right: titration profile at $900 \mathrm{~nm}$ (red triangles) with the superimposed distribution diagram of the species $\left[\mathrm{Cu}_{2}(\mathbf{L 1})\right]^{4+}$ (solid line) and $\left[\mathrm{Cu}_{2}(\mathbf{L 1})(\text { adip) }]^{2+}\right.$ (dotted line) vs. equivalents of the added guest, calculated for $\log K_{l l}=3.47(1)$. 

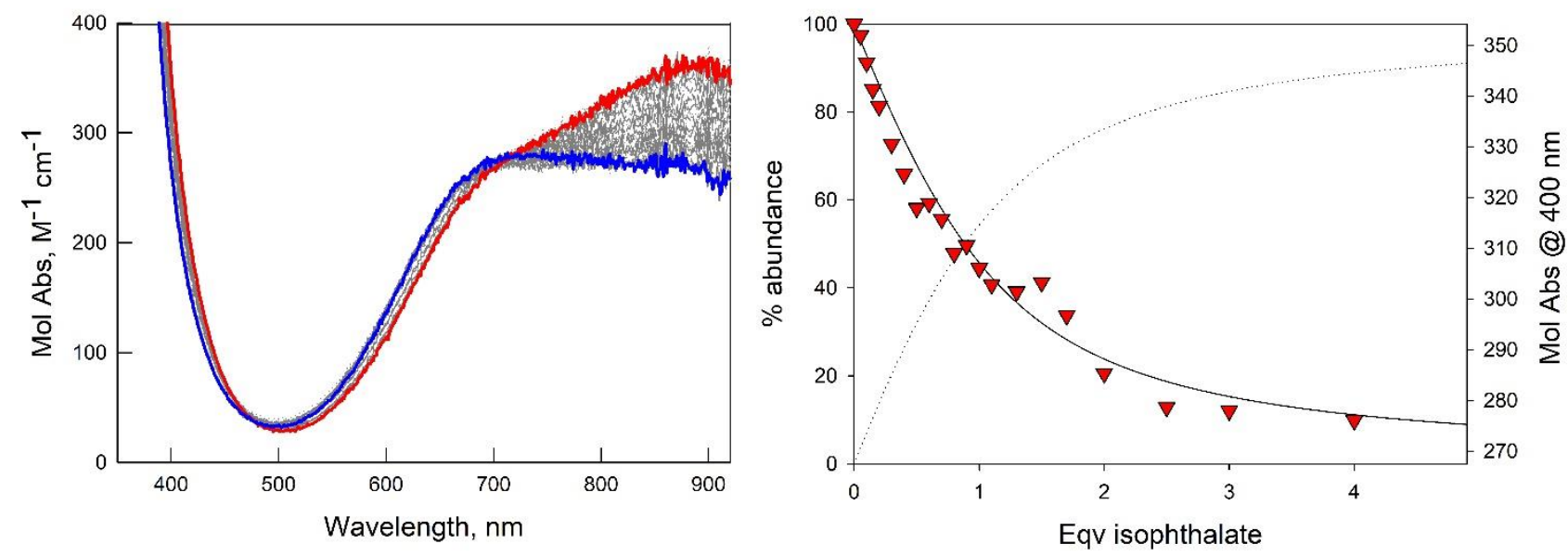

Figure S7. Left: UV-vis. spectra taken upon titration of $\left[\mathrm{Cu}_{2}(\mathbf{L 1})\right]^{4+} 50 \mu \mathrm{M}$ with isophthalate $12.5 \mathrm{mM}$ in dioxane/water $20 \% \mathrm{v} / \mathrm{v}$ at $\mathrm{pH} 7$ (HEPES $0.025 \mathrm{M}$, path length $10 \mathrm{~cm}$ ). The red and blue lines represent the spectra at 0 and 5 eqv. of the added anion, respectively. Right: titration profile at $400 \mathrm{~nm}$ (red triangles) with superimposed distribution diagram of the species $\left[\mathrm{Cu}_{2}(\mathbf{L 1})\right]^{4+}$ (solid line) and $\left[\mathrm{Cu}_{2}(\mathbf{L 1})(\text { isoph})\right]^{2+}$ (dotted line) vs. equivalents of the added guest, calculated for $\log K_{11}=4.98(4)$.
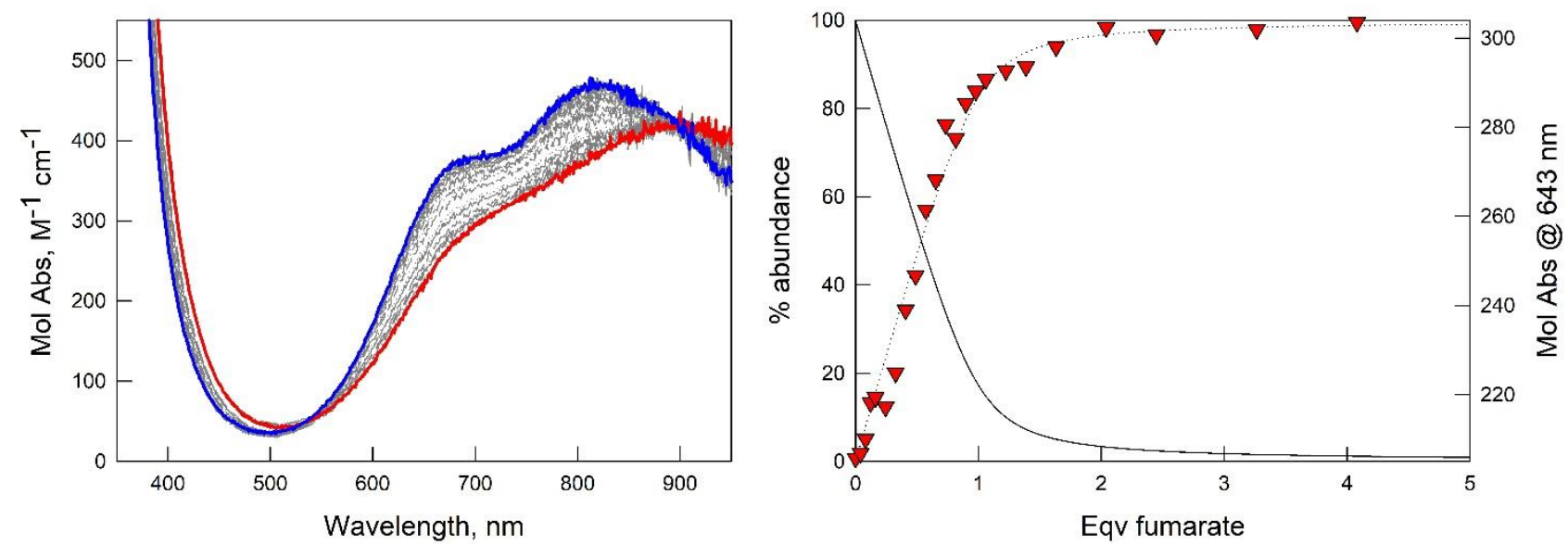

Figure S8. Left: UV-vis. spectra taken upon titration of $\left[\mathrm{Cu}_{2}(\mathbf{L 1})\right]^{4+} 50 \mu \mathrm{M}$ with fumarate $12.5 \mathrm{mM}$ in dioxane/water $20 \% \mathrm{v} / \mathrm{v}$ at pH 7 (HEPES $0.025 \mathrm{M}$, path length $10 \mathrm{~cm}$ ). The red and blue lines represent the spectra at 0 and 5 eqv. of the added anion, respectively. Right: titration profile at $643 \mathrm{~nm}$ (red triangles) with superimposed distribution diagram of the species $\left[\mathrm{Cu}_{2}(\mathbf{L 1})\right]^{4+}$ (solid line) and $\left[\mathrm{Cu}_{2}(\mathbf{L 1})(\mathrm{fum})\right]^{2+}$ (dotted line) vs. equivalents of the added guest, calculated for $\log K_{11}=5.76(2)$. 

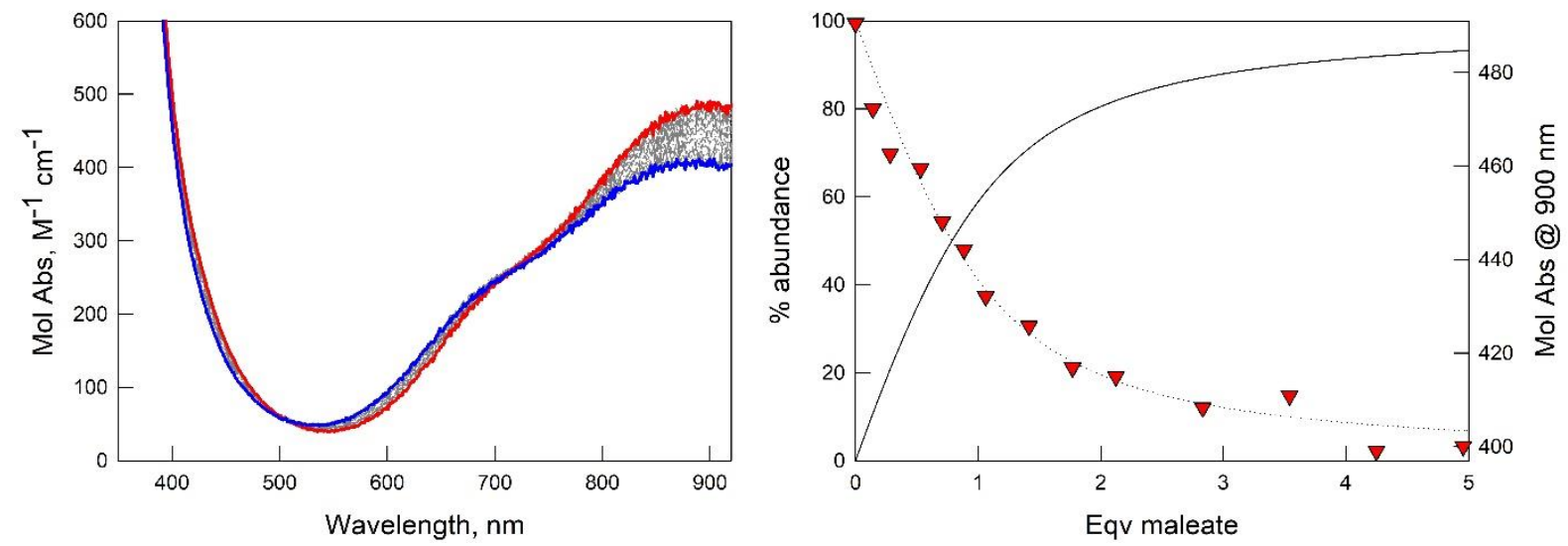

Figure S9. Left: UV-vis. spectra taken upon titration of $\left[\mathrm{Cu}_{2}(\mathbf{L 1})\right]^{4+} 0.55 \mathrm{mM}$ with maleate $0.10 \mathrm{M}$ in dioxane/water $20 \% \mathrm{v} / \mathrm{v}$ at pH 7 (HEPES $0.025 \mathrm{M}$, path length $1 \mathrm{~cm}$ ). The red and blue lines represent the spectra at 0 and 4 eqv. of the added anion, respectively. Right: titration profile at $900 \mathrm{~nm}$ (red triangles) with superimposed distribution diagram of the species $\left[\mathrm{Cu}_{2}(\mathbf{L 1})\right]^{4+}$ (solid line) and $\left[\mathrm{Cu}_{2}(\mathbf{L 1})(\mathrm{mal})\right]^{2+}$ (dotted line) vs. equivalents of the added guest, calculated for $\log K_{11}=3.65(5)$.

\subsection{UV-vis. titrations of $\left[\mathrm{Cu}_{2}(\mathrm{L2})\right]^{4+}$ in aqueous solution at $\mathrm{pH} 7$}

For the determination of binding constants, the solution of receptor was titrated with at least 100-fold more concentrated solution of the acid of the titled anion. For the titration with isophthalate, the corresponding $\mathrm{Na}^{+}$salt was used.
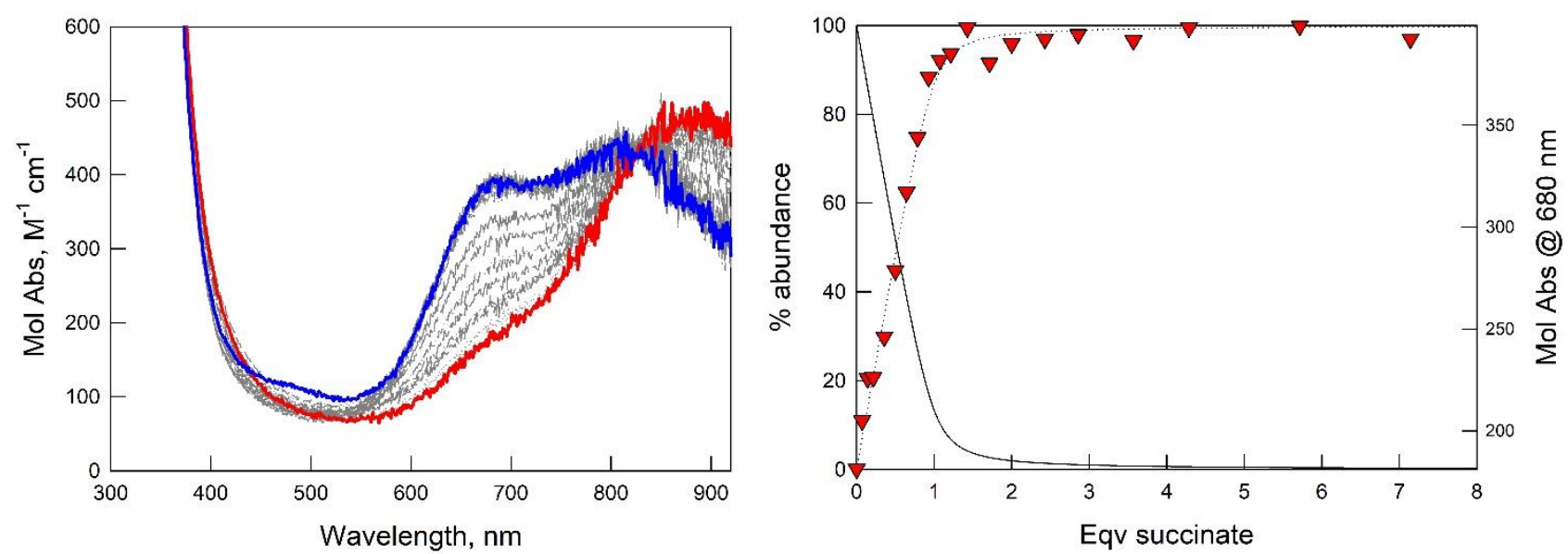

Figure S10. Left: UV-vis. spectra taken upon titration of $\left[\mathrm{Cu}_{2}(\mathbf{L 2})\right]^{4+} 50 \mu \mathrm{M}$ with succinate $5 \mathrm{mM}$ in water at pH 7 (HEPES $0.050 \mathrm{M}$, path length $10 \mathrm{~cm}$ ). The red and blue lines represent the spectra at 0 and 5 eqv. of the added anion, respectively. Right: titration profile at $680 \mathrm{~nm}$ (red triangles) with the superimposed distribution diagram of the species $\left[\mathrm{Cu}_{2}(\mathbf{L 2})\right]^{4+}$ (solid line) and $\left[\mathrm{Cu}_{2}(\mathbf{L 2})(\mathrm{suc})\right]^{2+}$ (dotted line) vs. equivalents of the added guest, calculated for an hypothetical $\log K_{11}$ value of 6.5 units. 

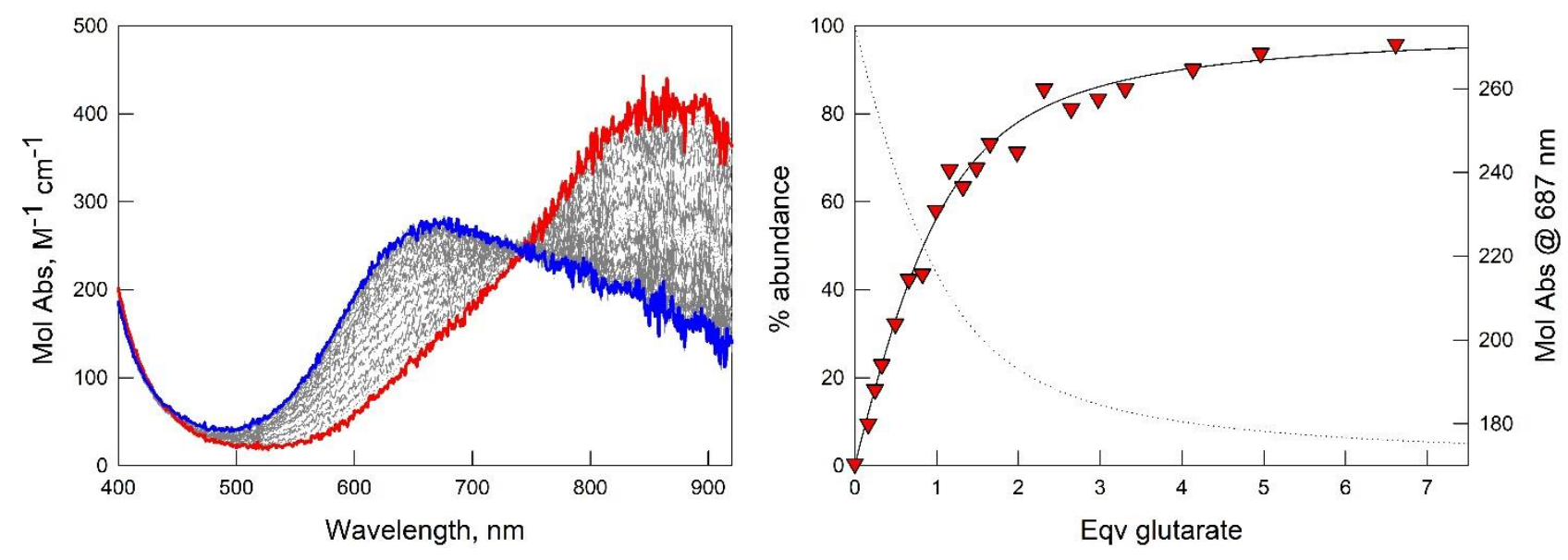

Figure S11. Left: UV-vis. spectra taken upon titration of $\left[\mathrm{Cu}_{2}(\mathbf{L 2})\right]^{4+} 50 \mu \mathrm{M}$ with glutarate $5 \mathrm{mM}$ in water at $\mathrm{pH} 7$ (HEPES $0.050 \mathrm{M}$, path length $10 \mathrm{~cm}$ ). The red and blue lines represent the spectra at 0 and 8 eqv. of the added anion, respectively. Right: titration profile at $687 \mathrm{~nm}$ (red triangles) with superimposed distribution diagram of the species $\left[\mathrm{Cu}_{2}(\mathbf{L 2})\right]^{4+}$ (solid line) and $\left[\mathrm{Cu}_{2}(\mathbf{L 2})(\text { glut })\right]^{2+}$ (dotted line) vs. equivalents of the added guest, calculated for $\log K_{I I}=5.39(1)$.
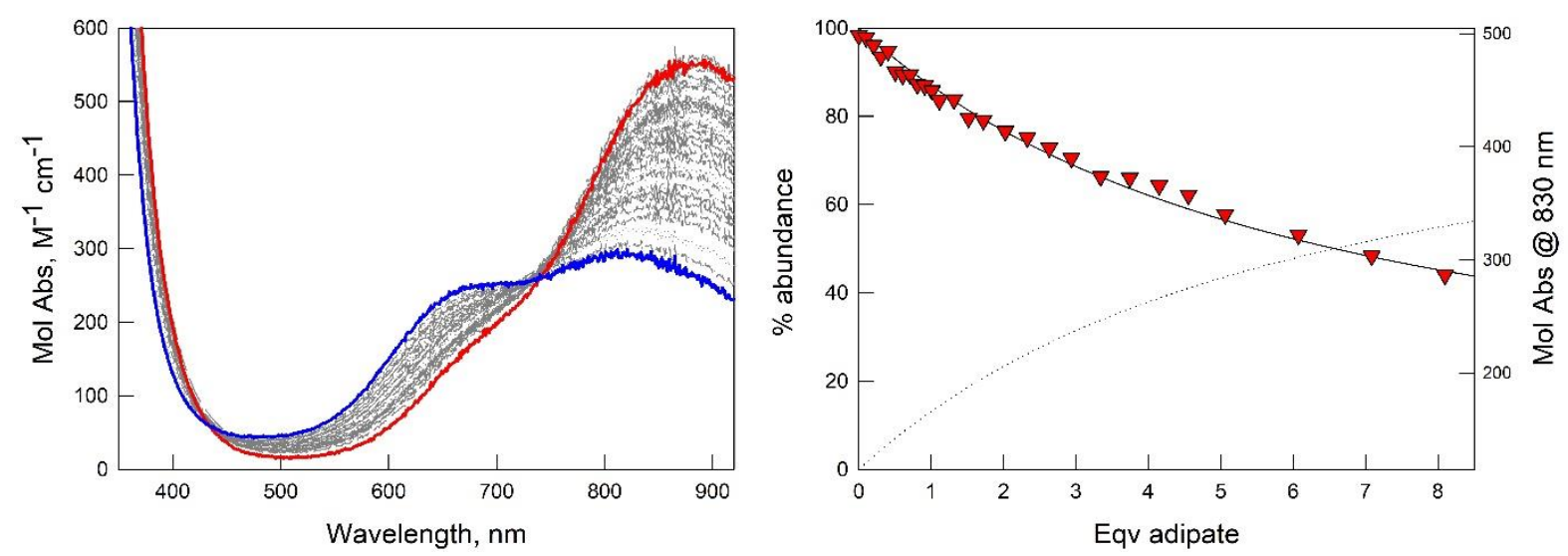

Figure S12. Left: UV-vis. spectra taken upon titration of $\left[\mathrm{Cu}_{2}(\mathbf{L 2})\right]^{4+} 0.55 \mathrm{mM}$ with adipate $50 \mathrm{mM}$ in water at $\mathrm{pH} 7$ (HEPES $0.05 \mathrm{M}$, path length $1 \mathrm{~cm}$ ). The red and blue lines represent the spectra at 0 and 8 eqv. of the added anion, respectively. Right: titration profile at $830 \mathrm{~nm}$ (red triangles) with superimposed distribution diagram of the species $\left[\mathrm{Cu}_{2}(\mathbf{L 2})\right]^{4+}$ (solid line) and $\left[\mathrm{Cu}_{2}(\mathbf{L 2})(\text { adip) }]^{2+}\right.$ (dotted line) vs. equivalents of the added guest, calculated for $\log K_{I I}=2.58(1)$. 

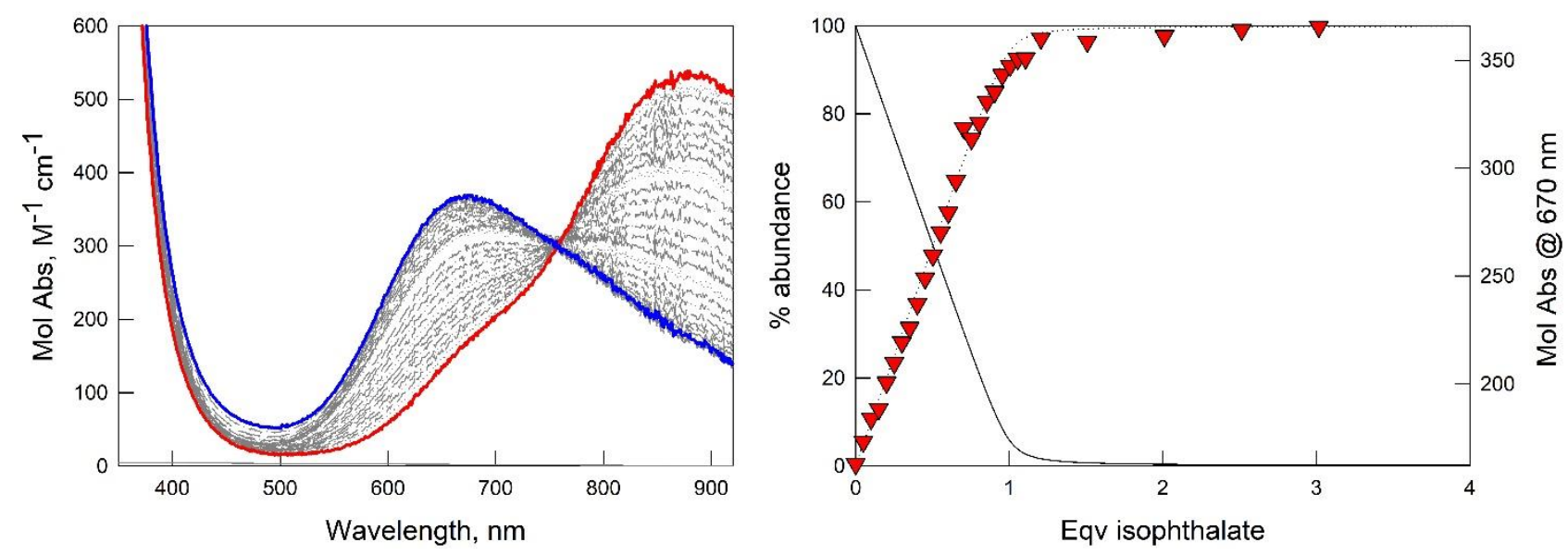

Figure S13. Left: UV-vis. spectra taken upon titration of $\left[\mathrm{Cu}_{2}(\mathbf{L 2})\right]^{4+} 0.50 \mathrm{mM}$ with isophthalate $50 \mathrm{mM}$ water at $\mathrm{pH} 7$ (HEPES $0.25 \mathrm{M}$, path length $1 \mathrm{~cm}$ ). The red and blue lines represent the spectra at 0 and 3 eqv. of the added anion, respectively. Right: titration profile at $670 \mathrm{~nm}$ (red triangles) with superimposed distribution diagram of the species $\left[\mathrm{Cu}_{2}(\mathbf{L 2})\right]^{4+}$ (solid line) and $\left[\mathrm{Cu}_{2}(\mathbf{L 2})(\text { isoph})\right]^{2+}$ (dotted line) vs. equivalents of the added guest, calculated for an hypothetical $\log K_{11}$ value of 6.5 units.
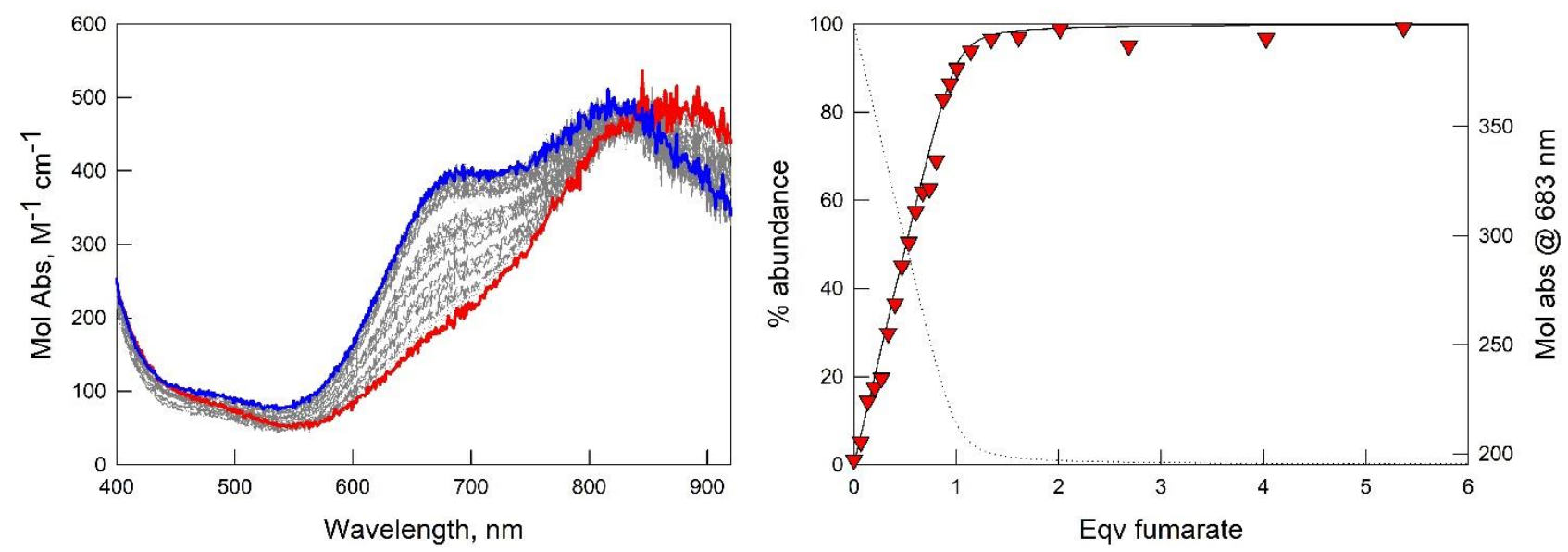

Figure S14. Left: UV-vis. spectra taken upon titration of $\left[\mathrm{Cu}_{2}(\mathbf{L} 2)\right]^{4+} 50 \mu \mathrm{M}$ with fumarate $5 \mathrm{mM}$ in water at pH 7 (HEPES $0.05 \mathrm{M}$, path length $10 \mathrm{~cm}$ ). The red and blue lines represent the spectra at 0 and 5 eqv. of the added anion, respectively. Right: titration profile at $683 \mathrm{~nm}$ (red triangles) with superimposed distribution diagram of $\left[\mathrm{Cu}_{2}(\mathbf{L} 2)\right]^{4+}$ (solid line) and $\left[\mathrm{Cu}_{2}(\mathbf{L 2})(\mathrm{fum})\right]^{2+}$ (dotted line) vs. equivalents of the added guest, calculated for an hypothetical $\log K_{l 1}$ value of 6.5 units. 

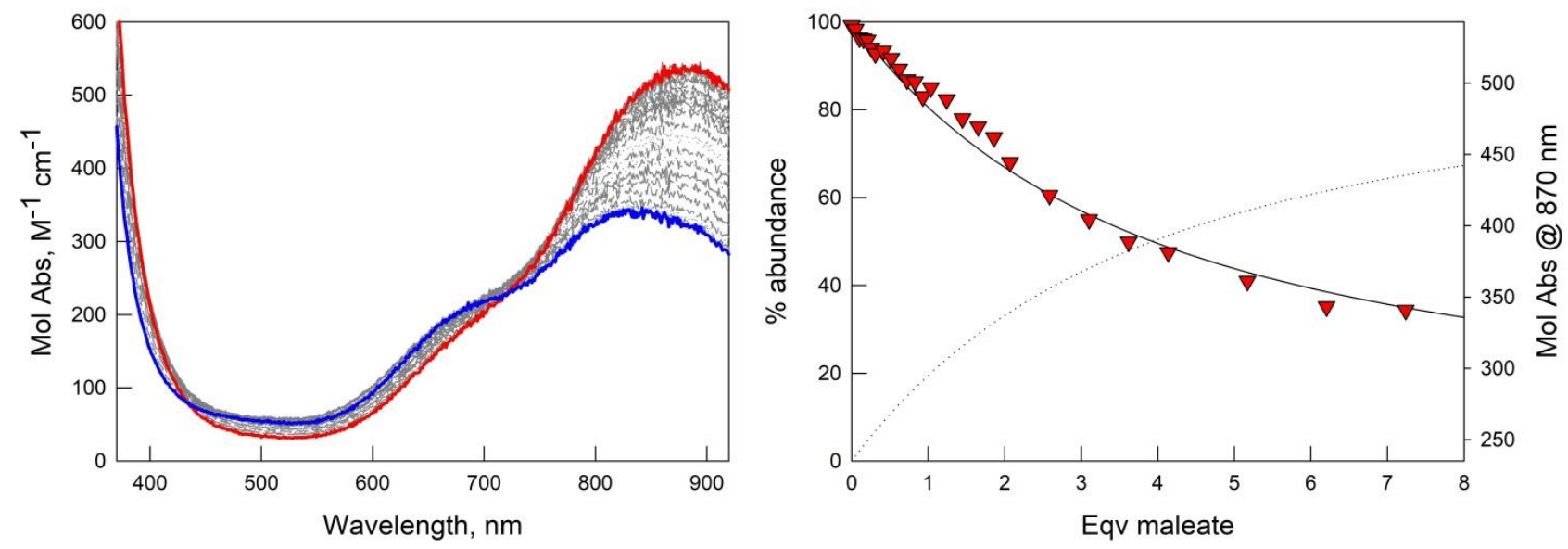

Figure S15. Left: UV-vis. spectra taken upon titration of $\left[\mathrm{Cu}_{2}(\mathbf{L 2})\right]^{4+} 0.50 \mathrm{mM}$ with maleate $50 \mathrm{mM}$ in water at $\mathrm{pH} 7$ (HEPES $0.05 \mathrm{M}$, path length $1 \mathrm{~cm}$ ). The red and blue lines represent the spectra at 0 and 9 eqv. of the added anion, respectively. Right: titration profile at $870 \mathrm{~nm}$ (red triangles) with superimposed distribution diagram of $\left[\mathrm{Cu}_{2}(\mathbf{L 2})\right]^{4+}$ (solid line) and $\left[\mathrm{Cu}_{2}(\mathbf{L} 2)(\mathrm{mal})\right]^{2+}$ (dotted line) vs. equivalents of the added guest, calculated for $\operatorname{LogK}_{11}=2.78(1)$.

\subsection{UV-vis. titration of $\left[\mathrm{Cu}_{2}(\mathrm{~L} 1)\right]^{4+}$ with succinate in dichloromethane}
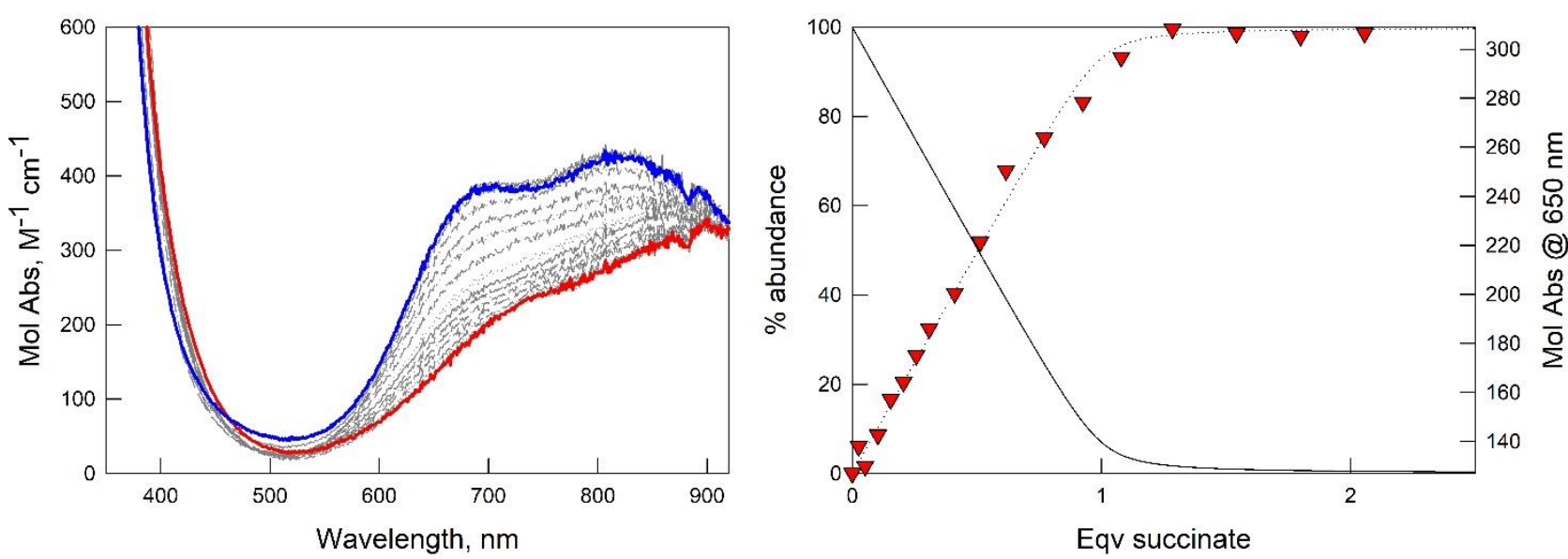

Figure S16. Left: UV-vis. spectra taken upon titration of $\left[\mathrm{Cu}_{2}(\mathbf{L 1})\right]^{4+} 30 \mu \mathrm{M}$ with $[\mathrm{TBA}]_{2} \mathrm{Succinate} 5 \mathrm{mM}$ in dichloromethane (path length $10 \mathrm{~cm}$ ). The red and blue lines represent the spectra at 0 and 2.2 eqv. of the added anion, respectively. Right: titration profile at $650 \mathrm{~nm}$ (red triangles) with superimposed distribution diagram of $\left[\mathrm{Cu}_{2}(\mathbf{L} \mathbf{1})\right]^{4+}$ (solid line) and $\left[\mathrm{Cu}_{2}(\mathbf{L 1})(\mathrm{suc})\right]^{2+}$ (dotted line), calculated for an hypothetical $\log K_{11}$ value of 6.5 units. 


\section{X-Ray diffraction studies}

Single crystals suitable for X-Ray diffraction studies were obtained by slow evaporation of an aqueous solution containing the relevent dicarboxylate sodium salt and the in-situ prepared complex: $\left[\mathrm{Cu}_{2}(\mathbf{L} 2)\right]\left(\mathrm{CF}_{3} \mathrm{SO}_{3}\right)_{4}$; in a 1:1 molar ratio.

Diffraction data for $\left[\mathrm{Cu}_{2}(\mathbf{L 2})(\right.$ glut $\left.)\right]\left(\mathrm{CF}_{3} \mathrm{SO}_{3}\right)_{2} \cdot 4\left(\mathrm{H}_{2} \mathrm{O}\right)$ crystal (greenish azure, $0.30 \times 0.26 \times$ $0.04 \mathrm{~mm}^{3}$ ), and $\left[\mathrm{Cu}_{2}(\mathbf{L 2})(\text { isoph })\right]_{3}\left(\mathrm{CF}_{3} \mathrm{SO}_{3}\right)_{6} \cdot 6\left(\mathrm{H}_{2} \mathrm{O}\right)$ crystal (greenish azure, $0.42 \times 0.20 \times 0.05$ $\mathrm{mm}^{3}$ ) were collected by means of a Bruker-AXS diffractometer equipped with the SMART-APEX $\mathrm{CCD}$ detector. Data collection was performed at room temperature with MoK $\alpha \mathrm{X}$-radiation $(\lambda=0.7107 \AA)$ and crystal data were reported on Table S3.

CCD frames were processed with the SAINT software ${ }^{9}$ and intensities were corrected for Lorentz and polarization effects; absorption effects were empirically evaluated by the SADABS software $^{10}$ and absorption correction was applied to the data. All crystal structures were solved by direct methods (SIR 97) ${ }^{11}$ and refined by full-matrix least-squares procedures on $F^{2}$ using all reflections (SHELXL-2018) ${ }^{12}$. Anisotropic displacement parameters were used for all non-hydrogen atoms. Hydrogens were placed at calculated positions and their positions refined according to a riding model.

In general, the X-ray diffraction quality of both synthetic crystals was poor and the $\left[\mathrm{Cu}_{2}(\mathbf{L 2}) \text { (isoph) }\right]_{3}\left(\mathrm{CF}_{3} \mathrm{SO}_{3}\right)_{6} \cdot 6\left(\mathrm{H}_{2} \mathrm{O}\right)$ crystal diffraction was particularly poor (diffracted intensities at $\theta$ angle greater than $22^{\circ}$ not observable with the available diffractometer). The poor diffraction quality resulted in a low accuracy for the atom positions of the triflate counterions and of the water solvent molecules. In particular, the large atom displacement parameters for atoms belonging to the counterions and to the water solvent molecules suggested the presence of unresolved positional disorder and imposed the use of soft geometrical restraints in the refinement of these atom positions. The crystal structure of the $\left[\mathrm{Cu}_{2}(\mathbf{L 2})(\mathrm{glut})\right]\left(\mathrm{CF}_{3} \mathrm{SO}_{3}\right)_{2} \cdot 4\left(\mathrm{H}_{2} \mathrm{O}\right)$ compound was refined restraining the molecular geometry of the triflate counterions to be similar by using the SAME instruction. In this crystal, some alternative positions for one triflate counterion were identified. The crystal structure of the $\left[\mathrm{Cu}_{2}(\mathbf{L 2})(\text { isoph })\right]_{3}\left(\mathrm{CF}_{3} \mathrm{SO}_{3}\right)_{6} \cdot 6\left(\mathrm{H}_{2} \mathrm{O}\right)$ was complicated by the presence of three similar but not symmetrically equivalent $\left[\mathrm{Cu}_{2}(\mathbf{L 2})(\text { isoph})\right]^{2+}$ anionic complexes. This compound was refined restraining the molecular geometry of the triflate counterions to the ideal one (by using the DFIX and DANG instructions) and restraining the three arms of each $\left[\mathrm{Cu}_{2}(\mathbf{L 2})\right]^{4+}$ dimetallic cage to show similar geometrical features (by using the SAME instruction). For both crystal structures, restraints on the atom displacement parameters (DELU and ISOR) were applied for atoms showing large and elongated thermal ellipsoids and positions for $\mathrm{H}$ atoms belonging to water solvent molecules were not determined.

Table S3. Crystal data for the studied compounds.

\begin{tabular}{lcc}
\hline & {$\left[\mathrm{Cu}_{2}(\mathbf{L 2})(\mathrm{glut})\right]\left(\mathrm{CF}_{3} \mathrm{SO}_{3}\right)_{2} \cdot 4\left(\mathrm{H}_{2} \mathrm{O}\right)$} & {$\left[\mathrm{Cu}_{2}(\mathbf{L 2})(\mathrm{isoph})\right]_{3}\left(\mathrm{CF}_{3} \mathrm{SO}_{3}\right)_{6} \cdot 6\left(\mathrm{H}_{2} \mathrm{O}\right)$} \\
\hline Formula & $\mathrm{C}_{55} \mathrm{H}_{74} \mathrm{Cu}_{2} \mathrm{~F}_{6} \mathrm{~N}_{8} \mathrm{O}_{14} \mathrm{~S}_{2}$ & $\mathrm{C}_{174} \mathrm{H}_{204} \mathrm{Cu}_{6} \mathrm{~F}_{18} \mathrm{~N}_{24} \mathrm{O}_{36} \mathrm{~S}_{6}$ \\
$M$ & 1376.42 & 4123.20 \\
Crystal system & monoclinic & triclinic \\
Space group & $P 2_{1} / c$ (no. 14$)$ & $P-1$ (no. 2) \\
$a(\AA)$ & $18.611(2)$ & $18.547(3)$ \\
$b(\AA)$ & $20.114(2)$ & $21.950(4)$ \\
$c(\AA)$ & $16.353(2)$ & $23.907(4)$ \\
\hline
\end{tabular}




\begin{tabular}{lcc}
\hline$\alpha\left(^{\circ}\right)$ & 90 & $100.574(2)$ \\
$\beta\left(^{\circ}\right)$ & $96.2020(10)$ & $102.098(2)$ \\
$\gamma\left({ }^{\circ}\right)$ & 90 & $96.155(2)$ \\
$V\left(\AA^{3}\right)$ & $6085.6(10)$ & $9247(3)$ \\
$\mathrm{Z}$ & 4 & 2 \\
$\rho_{\text {calcd }}\left(\mathrm{g} \cdot \mathrm{cm}^{-3}\right)$ & 1.502 & 1.481 \\
$\theta$ max $\left({ }^{\circ}\right)$ & 25 & 22 \\
Measured reflections & 42829 & 47534 \\
Unique reflections & 10700 & 22705 \\
$R_{\text {int }}$ & 0.047 & 0.045 \\
Strong data $\left[\mathrm{I}_{\mathrm{O}}>2 \sigma\left(\mathrm{I}_{\mathrm{O}}\right)\right]$ & 7164 & 10718 \\
$R 1, w R 2$ strong data & $0.0857,0.2437$ & $0.1454,0.3889$ \\
$R 1, w R 2$ all data & $0.1221,0.2784$ & $0.2256,0.4473$ \\
GoF & 1.045 & 1.369 \\
max/min residuals $\left(\mathrm{e} \AA^{-3}\right)$ & $1.05 /-0.84$ & $1.28 /-0.92$ \\
\hline
\end{tabular}

In spite of the poor quality of the available single crystals, the results of the crystallographic study are considered suitable to the aims of this work. In particular, the $\left[\mathrm{Cu}_{2}(\mathbf{L 2})\right]^{4+}$ dimetallic cage exhibits very similar molecular geometries in all moieties occurring in the two studied crystals. Furthermore, the C5-backbone common to the two dicarboxylate ions, i.e. the two terminal carbon atoms of the carboxylic groups and the three intermediate carbon atoms connecting them, were similarly positioned within the cryptand cavity. Figure S17 shows simplified sketches emphasizing the similarity among the molecular cage structures containing glutarate and the three different structures of the adduct with isophthalate. Figure S18 shows thermal ellipsoids of the dimetallic cages interacting with the two dicarboxylates.

For all studied complexes, the anionic guest resides in the cryptate cavity, exhibiting a cradle-like arrangement previously observed for the $\left[\mathrm{Cu}_{2}(\mathbf{L 2})\right]^{4+}$ complex interacting with fumarate and succinate ions. ${ }^{3}$ The two metal centers are bridged by the dicarboxylate ion and each $\mathrm{Cu}(\mathrm{II})$ cation is penta-coordinated by four $\mathrm{N}$ atoms of the tren subunit and by a carbonyl oxygen atom of the dicarboxylate. The incorporation of both glutarate and isophthalate ions into the receptor's cavity occurs through an increase of the $\mathrm{Cu}(\mathrm{II}) \cdots \mathrm{Cu}$ (II) separation of the dimetallic cage respect to the value observed in presence of fumarate and succinate ions. The $\mathrm{Cu}(\mathrm{II}) \cdots \mathrm{Cu}$ (II) separations are 8.95(1) $\AA$ in $\left[\mathrm{Cu}_{2}(\mathbf{L} 2)(\text { glut })\right]^{2+}$ and $8.92(1), 8.81(1)$, and $8.89(1) \AA$ for the three independent $\left[\mathrm{Cu}_{2}(\mathbf{L 2})(\text { isoph })\right]^{2+}$ cations, respectively, whereas the $\mathrm{Cu}(\mathrm{II}) \cdots \mathrm{Cu}(\mathrm{II})$ separations are $8.77(1) \AA$ in both $\left[\mathrm{Cu}_{2}(\mathbf{L} 2)(\text { fum })\right]^{2+}$ and $\left[\mathrm{Cu}_{2}(\mathbf{L 2})(\mathrm{suc})\right]^{2+}$ compounds. ${ }^{3}$ Geometrical features of the metal-center coordinations are reported in Table S4.
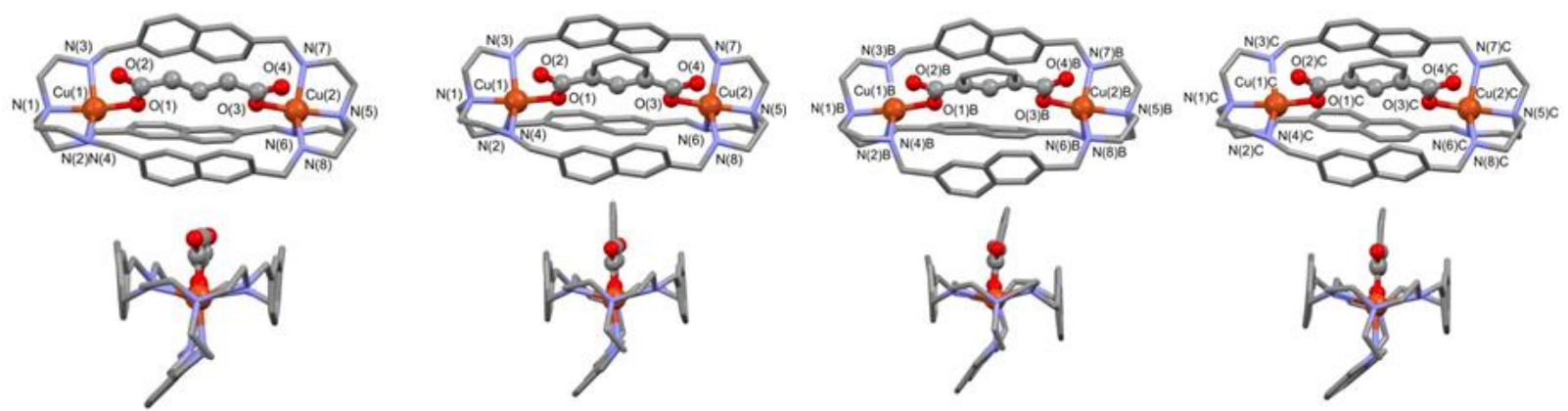

Figure S17. From the left, simplified sketches of the $\left[\mathrm{Cu}_{2}(\mathbf{L 2})(\mathrm{glut})\right]^{2+}$ molecular cation and of the three independent $\left[\mathrm{Cu}_{2}(\mathbf{L 2})(\text { isoph })\right]^{2+}$ molecular cations forming at the solid state. Sketches are drawn along two similar viewing 
directions in order to emphasize their geometrical similitudes (hydrogen atom were omitted for clarity). Atom names are reported only for $\mathrm{Cu}, \mathrm{N}$, and $\mathrm{O}$ atom sites.
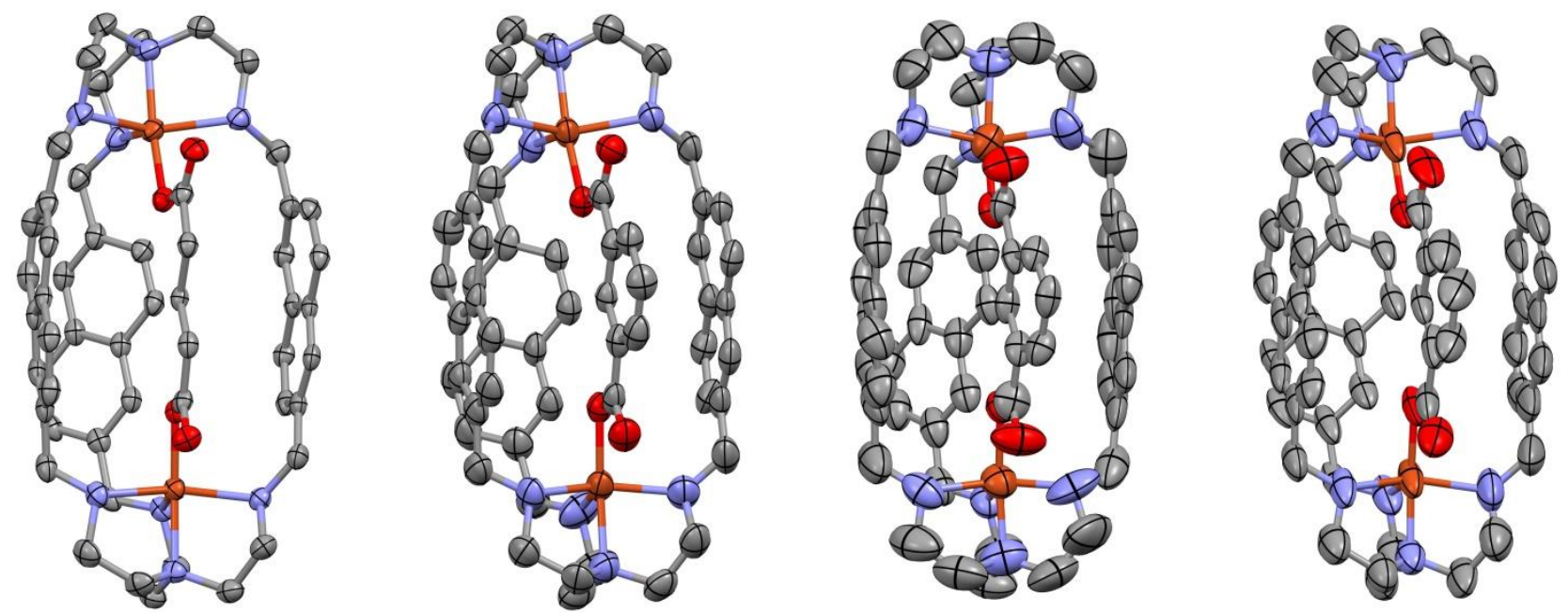

Figure S18. From the left, plot showing thermal ellipsoids for the $\left[\mathrm{Cu}_{2}(\mathbf{L 2})(\mathrm{glut})\right]^{2+}$ molecular cation and of the three independent $\left[\mathrm{Cu}_{2}(\mathbf{L 2})(\text { isoph})\right]^{2+}$ molecular cations (ellipsoids are drawn at the $30 \%$ probability level).

As for the compounds in the literature, the best plane of the dicarboxylate moieties remains almost parallel to the best plane of the naphthalene ring forming the two lateral arms of the cage (the dihedral angles for the studied molecular compounds are in the range 0.8-14.1 ${ }^{\circ}$ ). However, the separations between the centroid of the two naphthalene rings and the centroid of the dicarboxylate moieties are longer than observed, for instance, in the compound containing the unsaturated fumarate ion, thus suggesting minor face-to-face $\pi$-stacking interactions in presence of glutarate and isophthalate ions.

In particular, the two centroid-centroid separations in $\left[\mathrm{Cu}_{2}(\mathbf{L 2})(\mathrm{glut})\right]^{2+}$ compound are 3.50 and $3.51 \AA$, whereas those in the three independent $\left[\mathrm{Cu}_{2}(\mathbf{L 2})(\text { isoph })\right]^{2+}$ molecular cations are 3.70 and $3.81 \AA, 3.97$ and $4.13 \AA$, 3.77 and $3.80 \AA$, respectively. These values are to be compared to the centroid-centroid separations of 3.33 and $3.37 \AA$ occurring in the $\left[\mathrm{Cu}_{2}(\mathbf{L 2})(\text { fum) }]^{2+}\right.$ compound.

Table S4. Bond distances $(\AA)$ and bond angles $\left(^{\circ}\right)$ for the metal centers in the $\left[\mathrm{Cu}_{2}(\mathbf{L} 2)(\text { glut })\right]^{2+}$ and in the three not symmetrically equivalent $\left[\mathrm{Cu}_{2}(\mathbf{L} 2)(\text { isoph })\right]^{2+}$ molecular cations.

\begin{tabular}{|l|c|lll|}
\hline & {$\left[\mathrm{Cu}_{2}(\mathbf{L 2})(\mathrm{glut})\right]^{2+}$} & \multicolumn{3}{|c|}{$\left[\mathrm{Cu}_{2}(\mathbf{L 2})(\mathrm{isoph})\right]^{2+}$} \\
\hline $\mathrm{Cu}(1)-\mathrm{O}(1)$ & $1.934(4)$ & $1.957(9)$ & $1.977(10)$ & $1.947(12)$ \\
$\mathrm{Cu}(1)-\mathrm{N}(1)$ & $2.036(6)$ & $2.061(12)$ & $1.98(2)$ & $2.06(2)$ \\
$\mathrm{Cu}(1)-\mathrm{N}(2)$ & $2.377(5)$ & $2.371(14)$ & $2.349(14)$ & $2.37(2)$ \\
$\mathrm{Cu}(1)-\mathrm{N}(3)$ & $2.144(5)$ & $2.105(11)$ & $2.16(2)$ & $2.154(14)$ \\
$\mathrm{Cu}(1)-\mathrm{N}(4)$ & $2.133(5)$ & $2.097(13)$ & $1.93(2)$ & $2.12(2)$ \\
$\mathrm{Cu}(2)-\mathrm{O}(3)$ & $1.918(5)$ & $1.933(8)$ & $1.952(10)$ & $1.96(2)$ \\
$\mathrm{Cu}(2)-\mathrm{N}(5)$ & $2.043(6)$ & $2.035(12)$ & $2.11(2)$ & $2.12(2)$ \\
\hline
\end{tabular}




\begin{tabular}{|l|c|ccc|}
\hline $\mathrm{Cu}(2)-\mathrm{N}(6)$ & $2.402(6)$ & $2.445(11)$ & $2.377(13)$ & $2.361(14)$ \\
$\mathrm{Cu}(2)-\mathrm{N}(7)$ & $2.128(6)$ & $2.101(10)$ & $2.074(14)$ & $2.117(13)$ \\
$\mathrm{Cu}(2)-\mathrm{N}(8)$ & $2.155(6)$ & $2.156(10)$ & $2.09(2)$ & $2.172(13)$ \\
$\mathrm{O}(1)-\mathrm{Cu}(1)-\mathrm{N}(1)$ & $168.7(2)$ & $168.1(5)$ & $166.5(7)$ & $168.3(8)$ \\
$\mathrm{O}(1)-\mathrm{Cu}(1)-\mathrm{N}(2)$ & $109.56(18)$ & $110.5(4)$ & $115.3(5)$ & $112.2(7)$ \\
$\mathrm{O}(1)-\mathrm{Cu}(1)-\mathrm{N}(3)$ & $90.94(19)$ & $92.2(4)$ & $92.1(5)$ & $92.8(5)$ \\
$\mathrm{O}(1)-\mathrm{Cu}(1)-\mathrm{N}(4)$ & $95.40(18)$ & $95.3(4)$ & $92.0(6)$ & $95.7(6)$ \\
$\mathrm{N}(1)-\mathrm{Cu}(1)-\mathrm{N}(2)$ & $81.7(2)$ & $81.5(5)$ & $77.9(7)$ & $79.5(7)$ \\
$\mathrm{N}(1)-\mathrm{Cu}(1)-\mathrm{N}(3)$ & $84.7(2)$ & $83.5(5)$ & $86.8(9)$ & $83.1(6)$ \\
$\mathrm{N}(1)-\mathrm{Cu}(1)-\mathrm{N}(4)$ & $83.0(2)$ & $83.0(5)$ & $82.3(9)$ & $82.0(7)$ \\
$\mathrm{N}(2)-\mathrm{Cu}(1)-\mathrm{N}(3)$ & $107.3(2)$ & $109.0(6)$ & $104.3(6)$ & $106.5(6)$ \\
$\mathrm{N}(2)-\mathrm{Cu}(1)-\mathrm{N}(4)$ & $99.81(19)$ & $96.7(6)$ & $100.9(8)$ & $100.3(8)$ \\
$\mathrm{N}(3)-\mathrm{Cu}(1)-\mathrm{N}(4)$ & $148.3(2)$ & $148.7(5)$ & $149.8(9)$ & $146.3(9)$ \\
$\mathrm{O}(3)-\mathrm{Cu}(2)-\mathrm{N}(5)$ & $167.8(2)$ & $170.8(4)$ & $165.7(5)$ & $168.1(7)$ \\
$\mathrm{O}(3)-\mathrm{Cu}(2)-\mathrm{N}(6)$ & $111.7(2)$ & $109.2(4)$ & $113.1(4)$ & $111.8(6)$ \\
$\mathrm{O}(3)-\mathrm{Cu}(2)-\mathrm{N}(7)$ & $94.1(2)$ & $96.8(4)$ & $97.3(5)$ & $96.9(5)$ \\
$\mathrm{O}(3)-\mathrm{Cu}(2)-\mathrm{N}(8)$ & $91.2(2)$ & $90.9(4)$ & $91.9(5)$ & $90.2(6)$ \\
$\mathrm{N}(5)-\mathrm{Cu}(2)-\mathrm{N}(6)$ & $80.4(2)$ & $79.7(4)$ & $80.5(5)$ & $79.7(6)$ \\
$\mathrm{N}(5)-\mathrm{Cu}(2)-\mathrm{N}(7)$ & $83.8(3)$ & $83.4(4)$ & $83.6(7)$ & $83.7(5)$ \\
$\mathrm{N}(5)-\mathrm{Cu}(2)-\mathrm{N}(8)$ & $84.6(2)$ & $84.4(4)$ & $80.5(7)$ & $83.4(6)$ \\
$\mathrm{N}(6)-\mathrm{Cu}(2)-\mathrm{N}(7)$ & $100.5(2)$ & $100.4(4)$ & $100.9(6)$ & $100.6(6)$ \\
$\mathrm{N}(6)-\mathrm{Cu}(2)-\mathrm{N}(8)$ & $105.7(2)$ & $104.9(4)$ & $102.6(6)$ & $104.8(6)$ \\
$\mathrm{N}(7)-\mathrm{Cu}(2)-\mathrm{N}(8)$ & $149.1(2)$ & $149.5(4)$ & $148.9(6)$ & $148.8(6)$ \\
& & & & \\
& & 10.9 & \\
\hline
\end{tabular}




\section{HRMS-ESI spectra of $\left[\mathrm{Cu}_{2}(\mathrm{~L} 1)(\mathrm{suc})\right]^{2+}$}
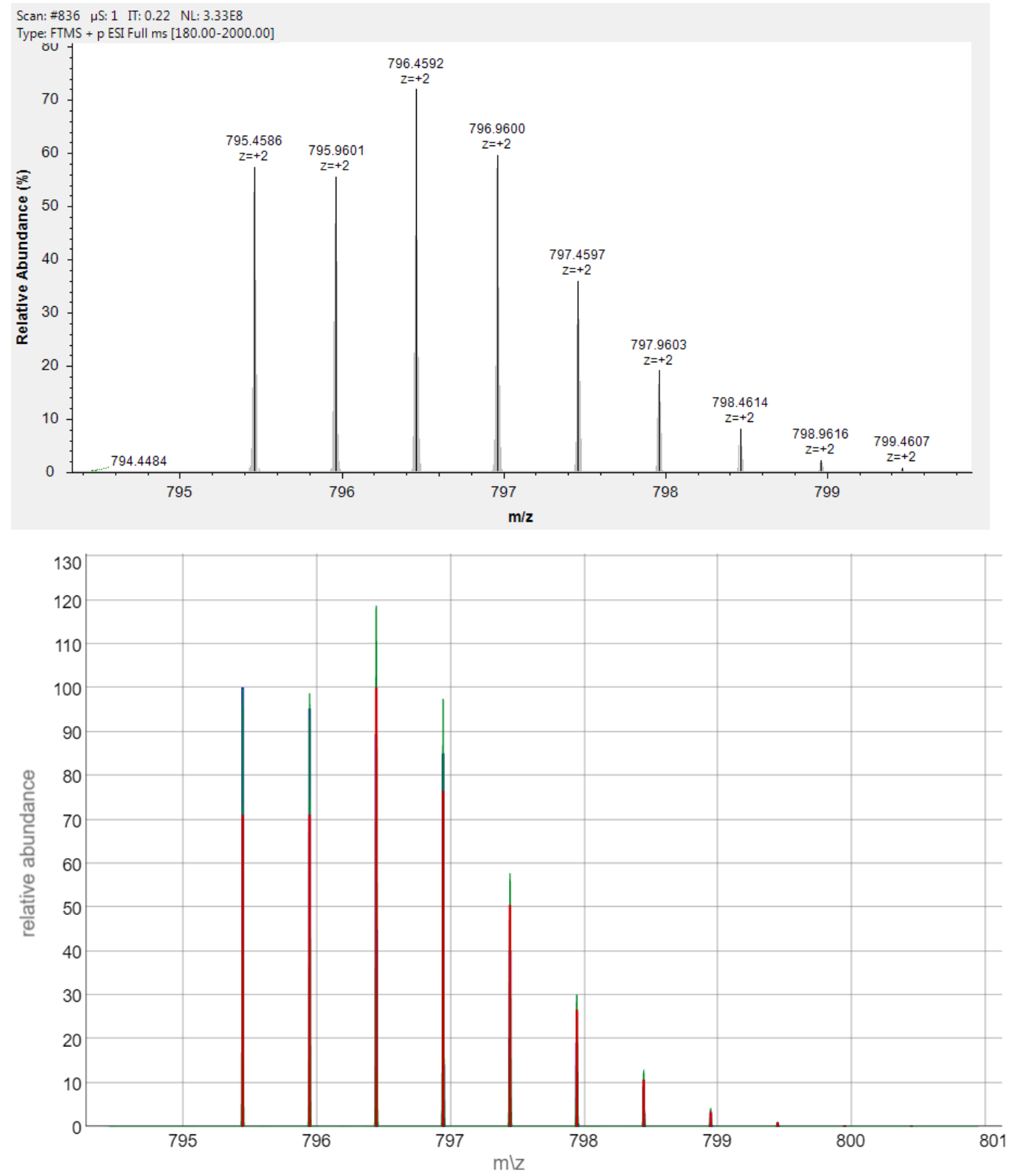

Figure S19. HRMS-ESI spectrum of a solution of $\left[\mathrm{Cu}_{2}(\mathbf{L 1})\right]^{4+}$ in $\mathrm{CH}_{3} \mathrm{CN}$, containing 1 eqv. of $\mathrm{Na}_{2} \mathrm{Suc}_{\text {. }}$

Up: zoom scan of the peak at $796.5492 \mathrm{~m} / \mathrm{z}$ obtained from the experimental HRMS-ESI spectrum. Bottom: calculated spectrum of the adduct $\left[\mathrm{Cu}_{2}(\mathbf{L} \mathbf{1})(\mathrm{suc})\right]^{2+}$. 


\section{Extraction experiments.}

\subsection{Experimental details}

Extraction experiments were performed with solutions of succinic acid $(1.0 \mathrm{mM})$, prepared in aqueous buffer (0.05 M HEPES) at $\mathrm{pH} \mathrm{7,} \mathrm{and} \mathrm{an} \mathrm{organic} \mathrm{phase} \mathrm{obtained} \mathrm{by} \mathrm{dilution} \mathrm{with}$ dichloromethane $(\mathrm{DCM})$ of a stock solution of $\left[\mathrm{Cu}_{2}(\mathbf{L 1})\right]\left(\mathrm{NO}_{3}\right)_{4}(9 \mathrm{mM})$ in DMSO. The final concentration of $\left[\mathrm{Cu}_{2}(\mathbf{L 1})\right]^{4+}$ in DCM was $0.20 \mathrm{mM}$ [the \% DMSO into the final solution being about $2 \% \mathrm{v} / \mathrm{v}]$.

The extraction of succinate into DCM was first verified by recording the UV-vis. spectrum of the solution, before and after mixing with the aqueous phase (Figure S20). The changes in the d-d bands at about 680 and $820 \mathrm{~nm}$, before and after extraction, can be attributed to the binding of succinate to the dicopper azacryptate in DCM. The formation of the $1: 1$ adduct, $\left[\mathrm{Cu}_{2}(\mathbf{L 1})(\mathrm{suc})\right]^{2+}$, is confirmed by comparing the spectra shown in Fig. S20 with those obtained upon titration of $\left[\mathrm{Cu}_{2}(\mathbf{L 1})\right]^{4+}$ with $[\mathrm{TBA}]_{2}$ suc in DCM (see Fig, S16).

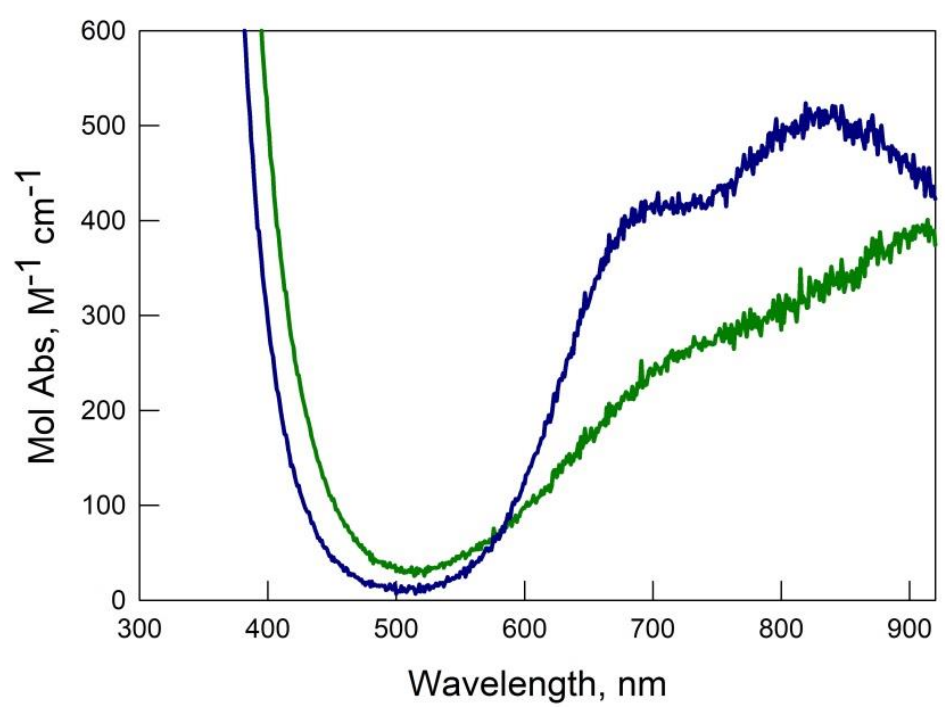

Figure S20. UV-vis. spectra of the solution of $\left[\mathrm{Cu}_{2}(\mathbf{L 1})\right]^{4+}(0.20 \mathrm{mM}$, path length $=1 \mathrm{~cm})$ in DCM before (green line) and after contact (blue line) with an aqueous solution of succinate $(1.0 \mathrm{mM})$.

The extraction of succinate from water into DCM was quantitatively evaluated by comparing the dicarboxylate concentration in the buffered aqueous solution, before and after mixing with the solution of $\left[\mathrm{Cu}_{2}(\mathbf{L 1})\right]^{4+}$ in DCM. The solutions were vigorously stirred for 20 minutes and then allowed to separate for 10 minutes. A blank experiment was run by mixing the aqueous solution of succinate with pure DCM under the same conditions as in the cryptate-mediated extraction. The procedure (for both extraction and blank experiments) was repeated seven times. For each repeat, the stock solution of succinic acid was freshly prepared in order to reduce experimental errors.

\subsubsection{HPLC-UV chromatographic analysis}

HPLC gradient grade acetonitrile and ultrapure water were purchased from VWR (Milan, Italy). The HPLC-UV apparatus consisted of a Shimadzu (Milan, Italy) LC-20AT solvent delivery module equipped with a DGU-20A3 degasser and interfaced with a SPD-20A UV detector. A Sepachrom 
Adamas C18-AQ $(250 \times 4.6 \mathrm{~mm}, 5 \mu \mathrm{m})$ column coupled with a Supelco Supelguard Ascentis C18 $(20 \times 2.1 \mathrm{~mm}, 5 \mu \mathrm{m})$ guard-column was used. After an equilibration period of $5 \mathrm{~min}, 20 \mu \mathrm{L}$ of each sample was injected in the HPLC system. The mobile phases were (a) $25 \mathrm{mM}$ aqueous $\mathrm{H}_{3} \mathrm{PO}_{4}(\mathrm{pH}$ 2.5 ) and (b) acetonitrile, working with an isocratic elution $10 \% \mathrm{~B}$ for $7 \mathrm{~min}$, followed by a washing step (linear gradient to $70 \% \mathrm{~B}$ until $9 \mathrm{~min}$, hold for $3 \mathrm{~min}$ ). The flow rate was $0.8 \mathrm{~mL} \mathrm{~min}^{-1}$ and the detection wavelength was $214 \mathrm{~nm}$.

Linearity was evaluated by analysis of succinate standard solutions prepared by dissolving succinic acid in HEPES buffer $(0.050 \mathrm{M}, \mathrm{pH} 7)$ in the concentration range $25-200 \mathrm{mg} \mathrm{L}^{-1}$ starting from a $1000 \mathrm{mg} \mathrm{L}^{-1}$ stock solution; examples of chromatograms are shown in Figure S21.

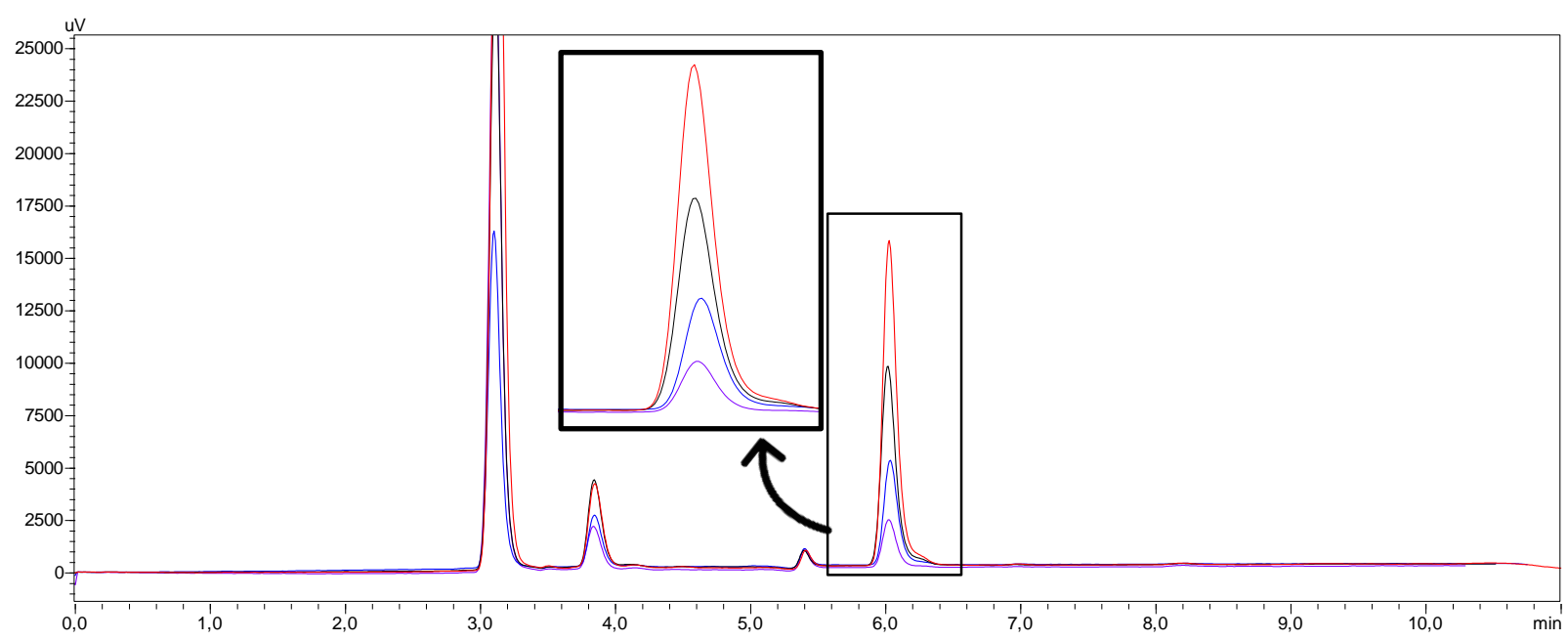

Figure S21. HPLC-UV chromatograms overlay of succinate standard solutions: $25 \mathrm{mg} \mathrm{L}^{-1}$ (violet line), $50 \mathrm{mg} \mathrm{L}^{-1}$ (blue line), $100 \mathrm{mg} \mathrm{L}^{-1}$ (black line), $150 \mathrm{mg} \mathrm{L}^{-1}$ (red line). Succinate retention time: $6.1 \mathrm{~min}$ (peak zoom in the inset).

Good linearity was observed on three independent five-point calibration lines $\left(\mathrm{r}^{2}>0.9982\right)$; an example of calibration curve graph is reported below:

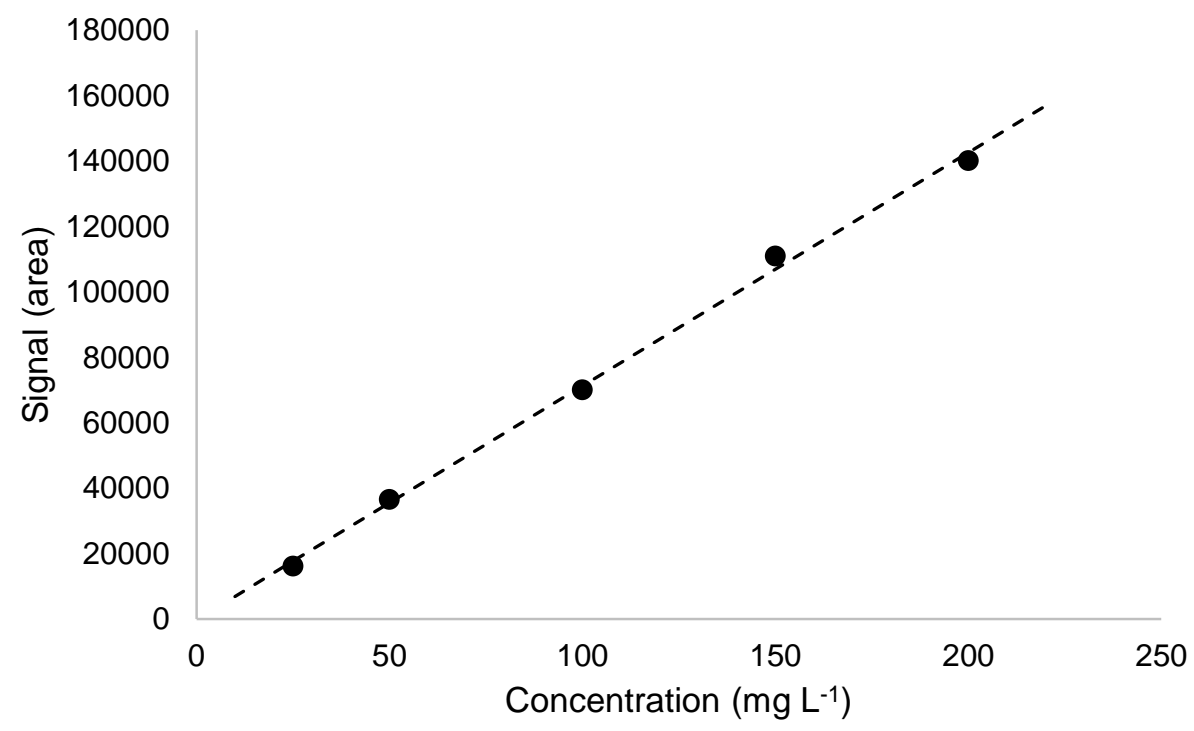

The percent loss of succinate in the aqueous phase in the extraction experiment was quantified by comparison with the analyte chromatographic peak obtained in the blank experiments, 
performed in parallel under the same conditions (but omitting the dicopper complex in the organic phase). An example of the chromatographic traces obtained in the extraction experiments is shown in Figure S22.

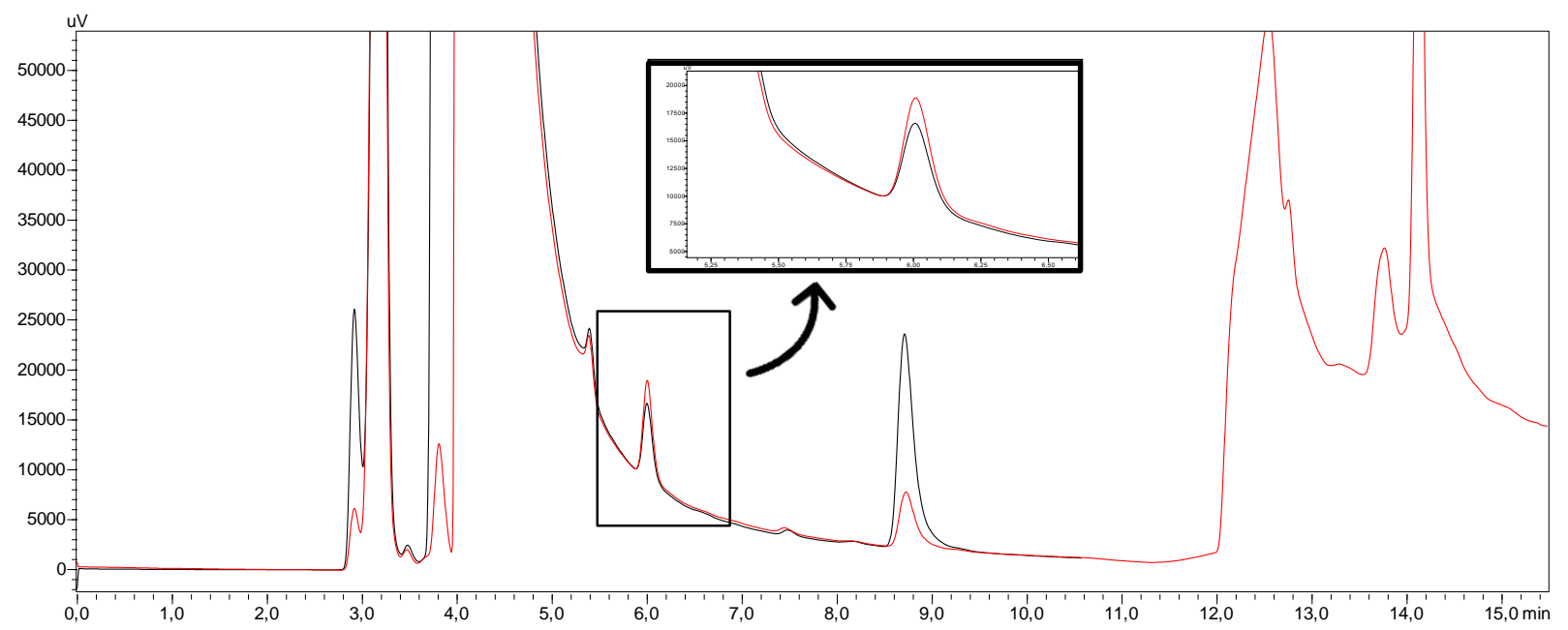

Figure S22. HPLC-UV chromatograms overlay of a succinate sample (in 0.050 M HEPES buffer) after contact with dichloromethane containing the dicopper cryptate (black line) and after contact with dichloromethane $(2.2 \% \mathrm{v} / \mathrm{v}$ DMSO, no cage) as control sample (red line). Succinate retention time: 6.1 min (peak zoom in the inset).

Due to the tailing of the peak eluting after 4 min observed in all samples from the extraction experiments, the succinate response has been evaluated by analysis of succinate standard solutions prepared in $0.050 \mathrm{M}$ HEPES buffer and contacted with the organic phase (containing $2.2 \% \mathrm{v} / \mathrm{v}$ DMSO but not the receptor), using the same experimental setup. Good linearity was observed in the working concentration range $\left(\mathrm{r}^{2}>0.9944\right)$. An example of calibration curve graph is shown below:

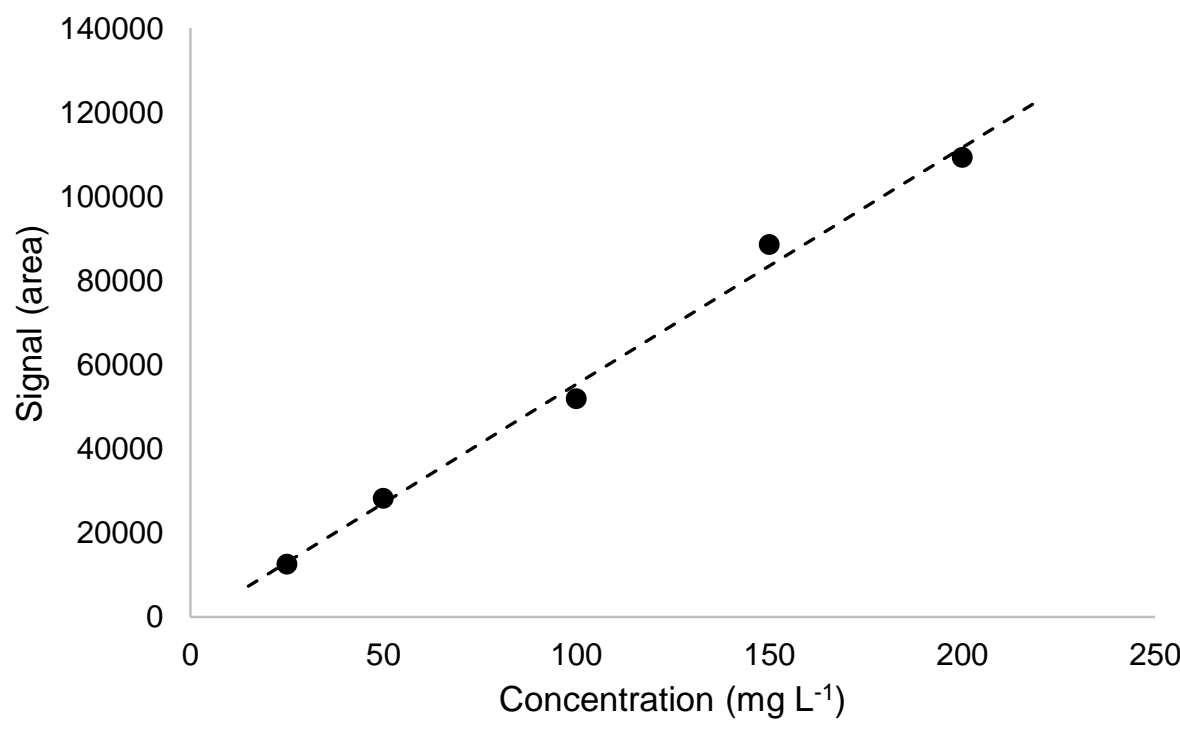

The succinate concentrations determined by HPLC-UV after the extraction experiments are reported in Table S5. 
Table S5. Results from the seven independent extraction experiments. The measured average extraction yield resulted to be $20 \pm 4 \%(n=7, \alpha 0.05)$.

\begin{tabular}{|l|l|l|}
\hline \multicolumn{2}{|l|}{ Succinate concentration in the aqueous phase $\left(\mathrm{mg} \mathrm{L}^{-1}\right)$} & \\
\hline Without azacryptate & With azacryptate & Extraction yield (\%) \\
\hline 142 & 101 & 28.4 \\
\hline 161 & 134 & 17.1 \\
\hline 143 & 113 & 20.9 \\
\hline 152 & 127 & 16.8 \\
\hline 119 & 91 & 24.2 \\
\hline 163 & 132 & 18.7 \\
\hline 154 & 128 & 16.7 \\
\hline
\end{tabular}




\section{Characterization}

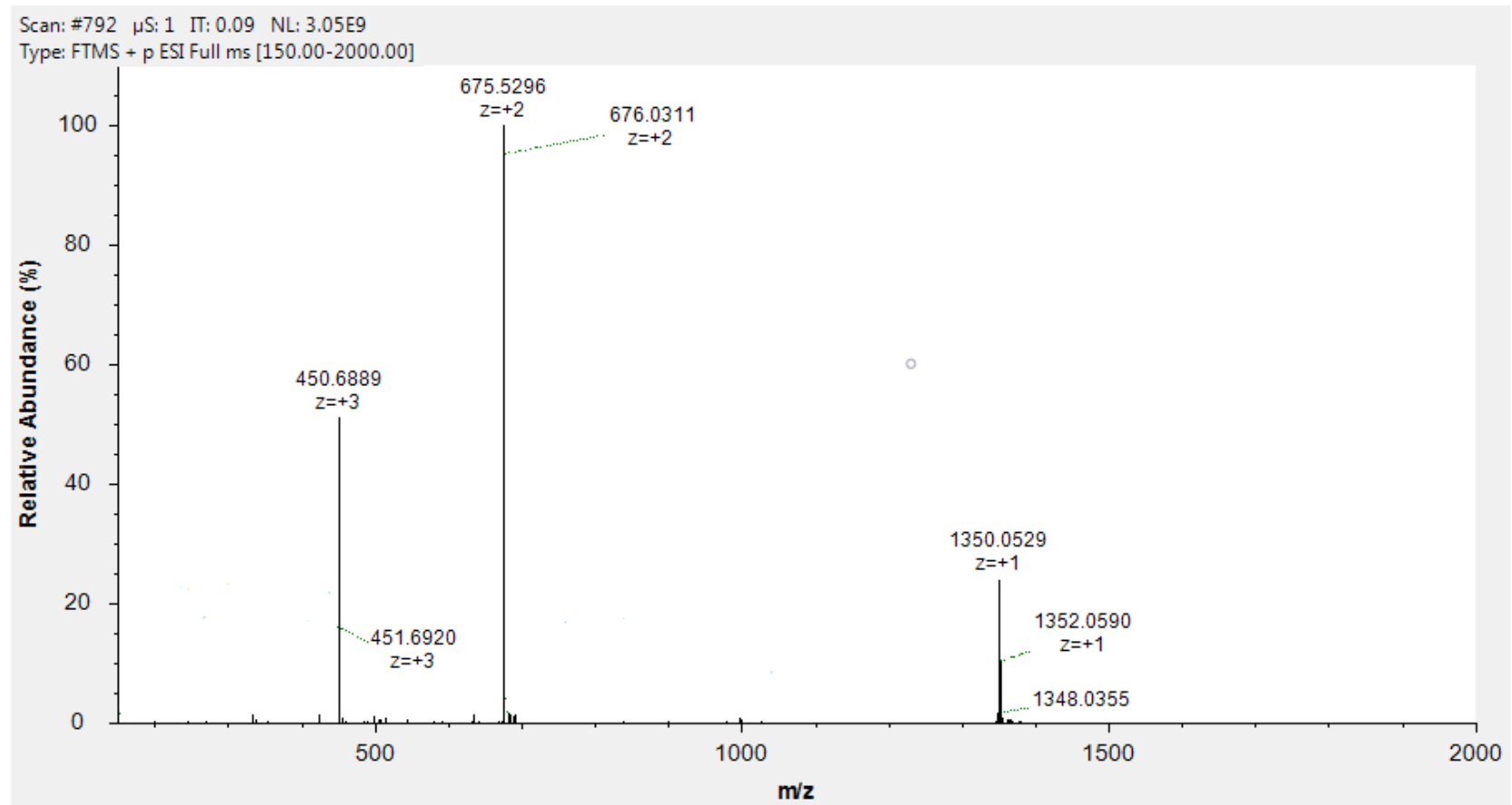

Figure S23. HRMS-ESI spectrum of $\mathbf{L} 1$ in methanol. Peaks at $\mathrm{m} / \mathrm{z} 450.6889(+3), 675.5296(+2)$ and $1350.0529(+1)$ are attributable to the species $\left[\mathrm{M}+3 \mathrm{H}^{+}\right],\left[\mathrm{M}+2 \mathrm{H}^{+}\right]$and $\left[\mathrm{M}+\mathrm{H}^{+}\right]$, respectively. 

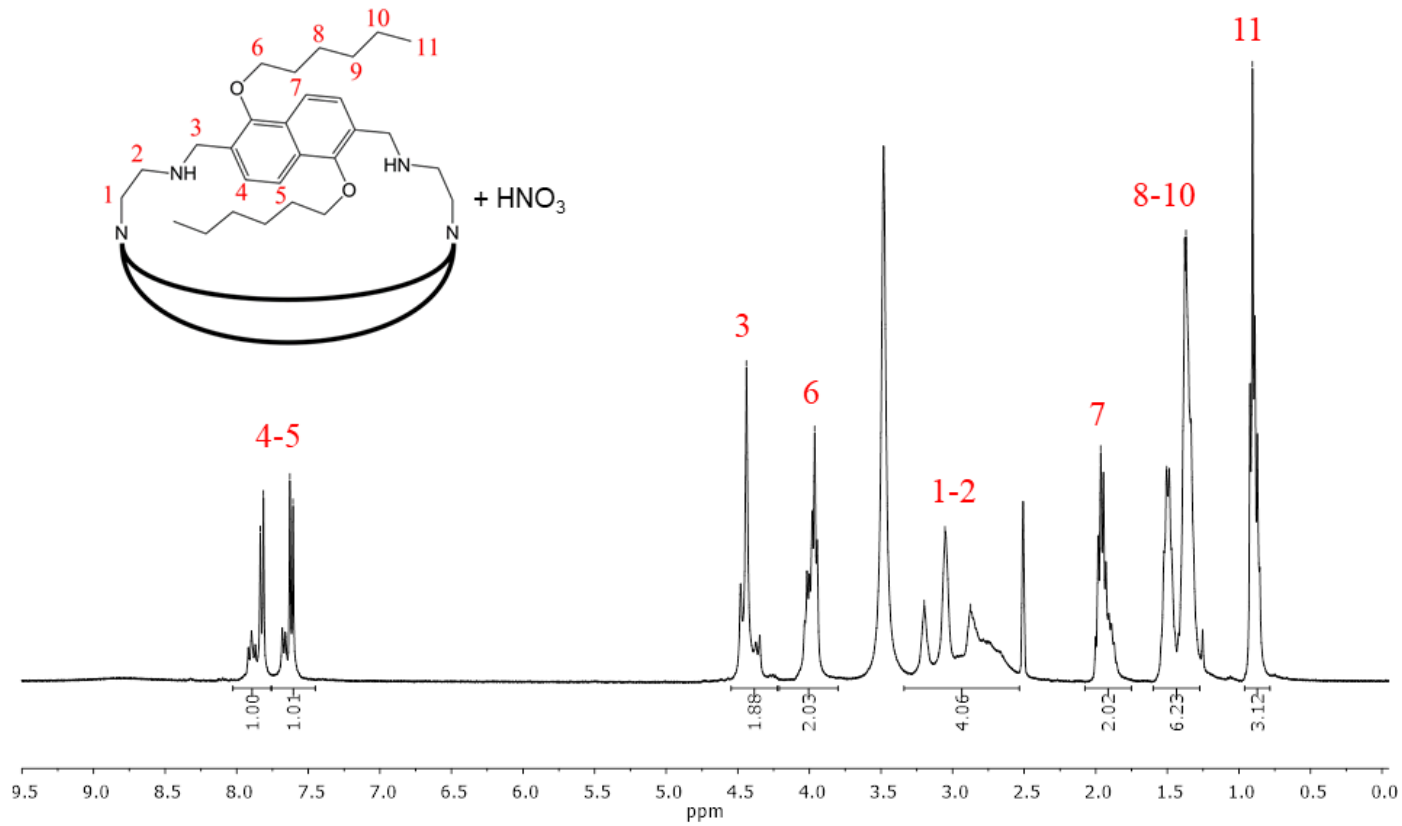

Figure S24. ${ }^{1} \mathrm{H}-\mathrm{NMR}$ spectrum of $\mathbf{L 1}(10 \mathrm{mM})$ in $\mathrm{d}_{6}$-DMSO, recorded at $80^{\circ} \mathrm{C}$ and after the addition of aliquots of $\mathrm{HNO}_{3}$ (in $\mathrm{D}_{2} \mathrm{O}$ ) to the solution. At room temperature and without acidification, the peaks were actually too large to allow a safe interpretation of the spectrum. Integrals are calculated on one portion of the molecule (as shown in the inset).

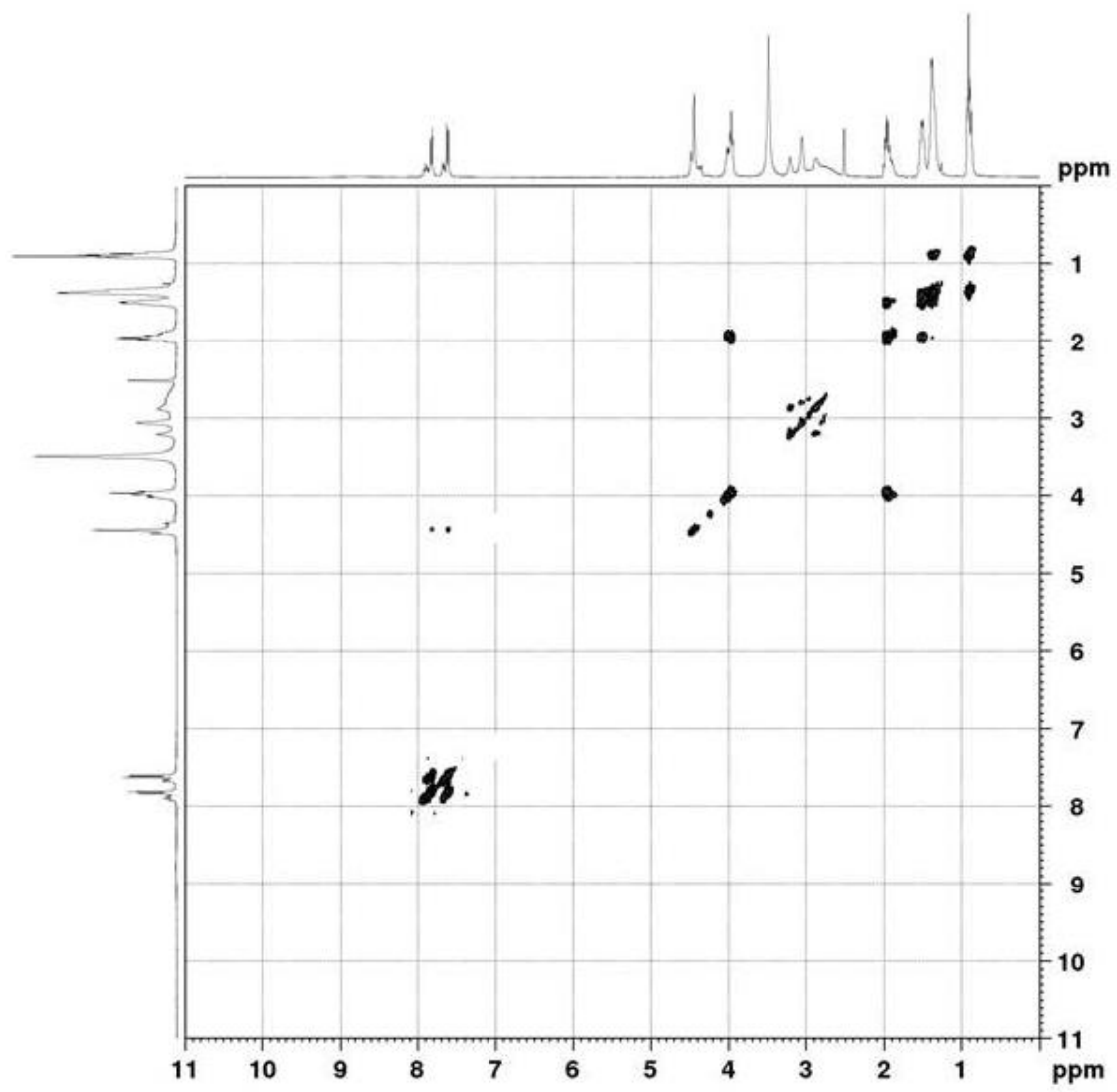

$\cos Y \mathrm{~T}=80^{\circ} \mathrm{C}$

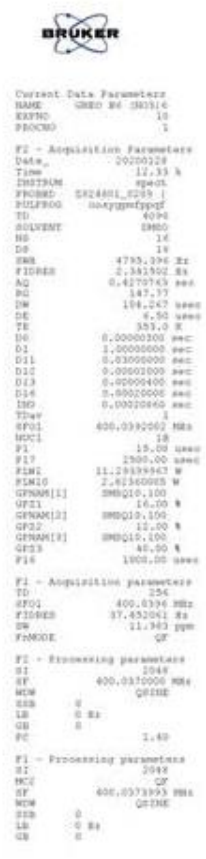

Figure S25. ${ }^{1} \mathrm{H}-{ }^{1} \mathrm{H}$ COSY spectrum of $\mathbf{L 1}$ in $\mathrm{d}_{6}-\mathrm{DMSO}\left(+\mathrm{HNO}_{3}\right)$ recorded at $80^{\circ} \mathrm{C}$. 


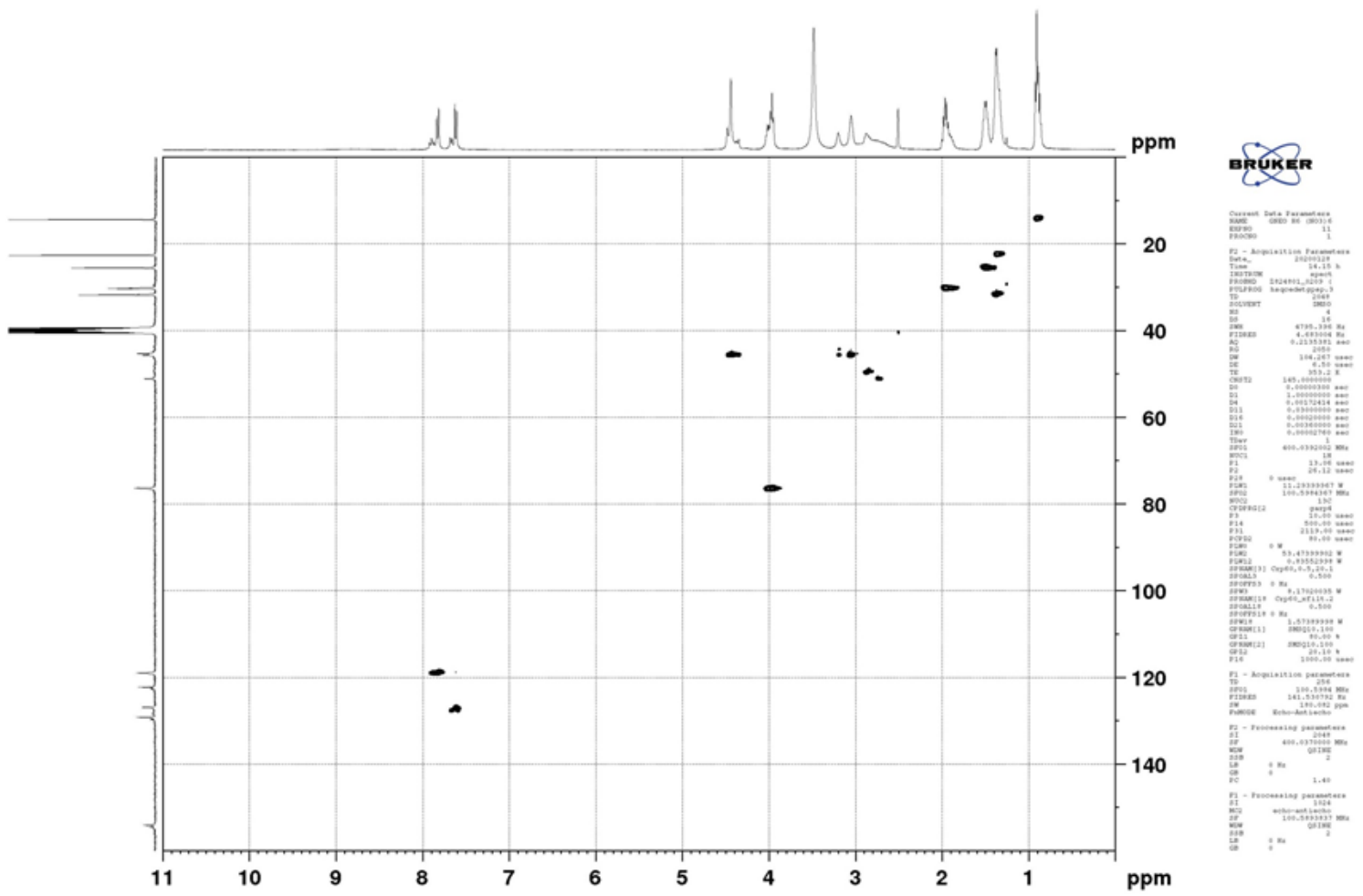

Figure S26. ${ }^{1} \mathrm{H}^{13}{ }^{13} \mathrm{C} \mathrm{HSQC}$ spectrum of $\mathbf{L 1}$ in $\mathrm{d}_{6}-\mathrm{DMSO}\left(+\mathrm{HNO}_{3}\right)$ recorded at $80^{\circ} \mathrm{C}$ 


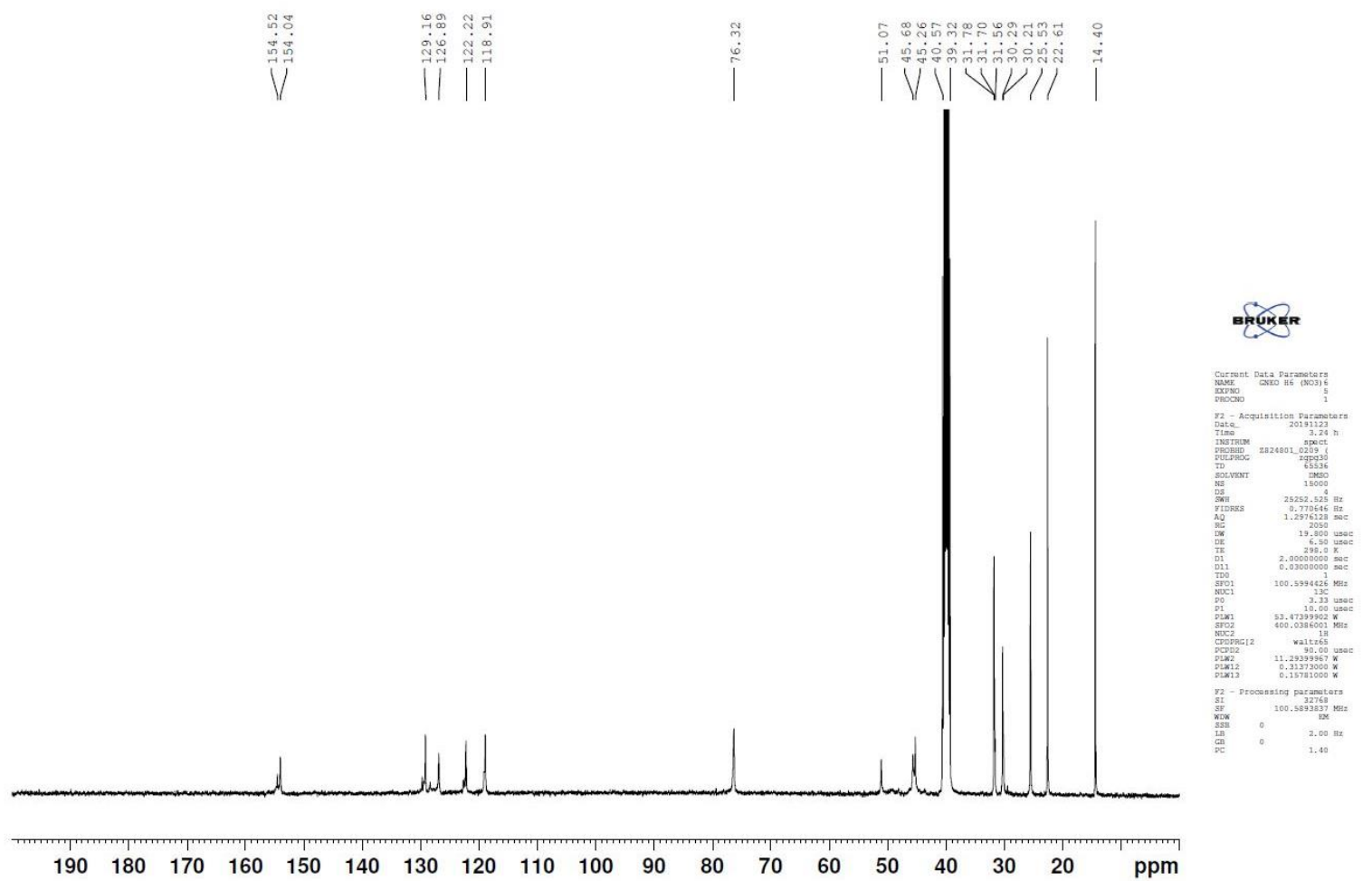

Figure S27. ${ }^{13} \mathrm{C}-\mathrm{NMR}$ of $\mathbf{L 1}$ in $\mathrm{d}_{6}$-DMSO recorded at $25^{\circ} \mathrm{C}$. 


\section{References}

[1] Urban, M.; Durka, K.; Jankowski, P.; Serwatowski, J.; Luliński, S. Highly Fluorescent Red-Light Emitting Bis(boranils) Based on Naphthalene Backbone. J. Org. Chem. 2017, 82, 8234-8241.

[2] Allen, C. R.; Richard, P. L.; Ward, A. J.; van de Water, L. G. A.; Masters, A. F.; Maschmeyer, T. Facile synthesis of ionic liquids possessing chiral carboxylates. Tetrahedron Lett. 2006, 47, 73677370.

[3] Xie, G. Y.; Jiang, L.; Lu, T. B. Discrimination of Cis-Trans Isomers by Dinuclear Metal Cryptates at Physiological pH: Selectivity for Fumarate vs. Maleate. Dalt. Trans. 2013, 42 (39), 14092 14099.

[4] Gran, G. Determination of the equivalence point in potentiometric titrations. Part II Analyst 1952, 77, 661-671.

[5] Gans, P.; Sabatini, A.; Vacca, A. Investigation of Equilibria in Solution. Determination of Equilibrium Constants with the HYPERQUAD Suite of Programs. Talanta 1996, 43, 1793-1802.

[6] (a) Dawson, R. M. C., et al., Data for Biochemical Research, $3^{\text {rd }}$ ed., 1986, Oxford University Press, New York, NY; (b) Lide, D. R. CRC Handbook of Chemistry and Physics, $84^{\text {th }}$ ed., 2003, CRC Press, Boca Raton, FL.

[7] Thordarson, P. Determining association constants from titration experiments in supramolecular chemistry. Chem. Soc. Rev. 2011, 40, 1305-1323.

[8] Wilcox, C. S. Frontiers in Supramolecular Chemistry and Photochemistry, VCH Weinheim, Germany, 1991, 123-143.

[9] Bruker, SAINT Software Reference Manual. Version 6, Bruker AXS Inc., Madison, Wisconsin, USA, 2003.

[10] Krause, L.; Herbst-Irmer, R.; Sheldrick, G. M.; Stalkeand, D. Comparison of silver and molybdenum microfocus X-ray sources for single-crystal structure determination. J. Appl. Crystallogr. 2015, 48, 310.

[11] Altomare, A.; Burla, M. C.; Camalli, M.; Cascarano, G. L.; Giacovazzo, C.; Guagliardi, A.; Moliterni, A. G.; Polidori, G.; Spagna, R. J. SIR97: a new tool for crystal structure determination and refinement. J. Appl. Crystallogr. 1999, 32, 115-119.

[12] Sheldrick, G. M. Crystal structure refinement with SHELXL. Acta Crystallogr. 2015, C71, 3-8. 
